\title{
The Synergistic Effect of Thermal Collectors Rotation in relation to Their Energy Efficiency and Stagnation Compared with the Static Thermal System in the Conditions of Central Europe
}

\author{
Miroslav Rimar, ${ }^{1}$ Marcel Fedak, ${ }^{1}$ Michal Hatala, ${ }^{2}$ and Peter Smeringai ${ }^{1}$ \\ ${ }^{1}$ Department of Process Technique, Faculty of Manufacturing Technologies with seat in Prešov, Sturova 31, 080 01 Prešov, Slovakia \\ ${ }^{2}$ Department of Manufacturing Technologies, Faculty of Manufacturing Technologies with seat in Prešov, Sturova 31, \\ 08001 Prešov, Slovakia
}

Correspondence should be addressed to Marcel Fedak; marcel.fedak@tuke.sk

Received 2 February 2015; Accepted 12 March 2015

Academic Editor: Fuqiang Wang

Copyright (C) 2015 Miroslav Rimar et al. This is an open access article distributed under the Creative Commons Attribution License, which permits unrestricted use, distribution, and reproduction in any medium, provided the original work is properly cited.

\begin{abstract}
The presented paper deals with the issue of the efficient use of solar energy potential gained from thermal panels via tracking the Sun's trajectory. Based on long-term measurements of the selected parameters, the efficiency of the installed system in relation to the ecliptic was evaluated in the static regime as well as in a rotary regime. In the comparison of rotary and fixed system of the collectors the presented results show an increase of the effectiveness of rotary one during the period of the day. On closer view the increase is not constant. During the day it varies: the most significant increase is in the afternoon, while the time from 10:30 a.m. to 1:00 p.m. the effectiveness of both systems almost identical. The utilisation of the rotary system as a suitable instrument for the elimination of the system stagnation was also evaluated.
\end{abstract}

\section{Introduction}

The annual amount of solar energy reaching the Earth's surface in the territory of Slovakia is from 1,100 to 1,325 kWh per unit area $\left(1 \mathrm{~m}^{2}\right)[1-4]$. Solar radiation either can be used directly by solar thermal collectors or it can be converted into another form of energy, particularly electricity in photovoltaic cells $[5,6]$. The use of photothermal and photovoltaic systems has reached such a stage of development that it is possible to consider their economic utilisation especially if the gained energy is used for the regulable systems operation.

For the optimum capturing of solar energy and its use by collectors, their appropriate orientations is essential so that a significant amount of sunbeams can be absorbed [7-11]. The collectors orientation is given by an azimuth angle $\alpha \mathrm{S}$. The most preferred is the orientation to the south, where the highest values of the theoretically possible amount of solar energy falling per day are achieved. Another factor influencing the efficiency of solar energy capturing is a tilt angle $\alpha$ from the horizontal plane [8-10]. The collector can take a maximum amount of energy if a plane of collectors surface forms a right angle to the incident solar radiation. In our climatic conditions, the optimum collectors tilt angle $\alpha$ is between $30^{\circ}$ and $45^{\circ}$ during a day and a year with the summer utilization and with the winter utilization it is from $60^{\circ}$ to $90^{\circ}$. If the collectors are utilised throughout a year, it is advantageous to change their tilt depending on the season $[8,12,13]$. The best way to collect maximum daily energy is to use tracking systems. A tracker is a mechanical device that follows the direction of the Sun on its daily sweep across the sky [10].

A photothermic system is based on the solar collector, which collects, absorbs, and changes solar radiation into heat discharged by a fluid or air to the place of use or accumulation [6]. The most common type is a flat-plate solar liquid collector. The basic construction parts (Figure 1) are the cover glass, absorbent layer, piping distribution, thermal insulation, and frame construction $[6,14]$. The function of the transparent 


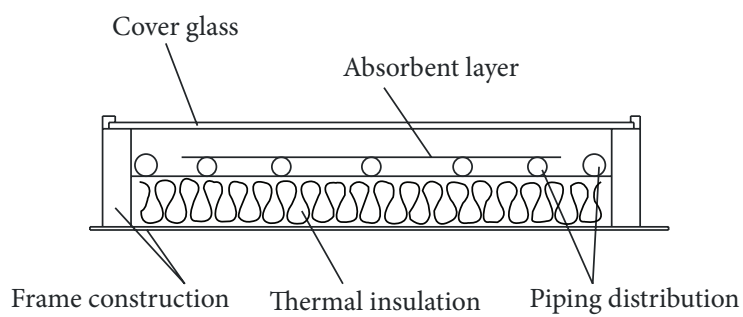

FIGURE 1: Diagram of a flat-plate collector.

layer is to reduce a heat loss via convection and dissipation to the environment as well as to increase the thermal efficiency of the collector. The cover layer is transparent and consists of a single, double, or triple glazing, which transmits the Sun radiation and prevents a back reflection of infrared radiation [14]. The most important functional element of a flat-plate collector is the so called absorber, which absorbs the incident Sun radiation and transmits it as a heat to a heat transfer medium. The absorber is a well-conductive thin metal plate with a differently shaped surface affecting the flow of a heat transfer substance. The surface modification ensures a high absorption of solar radiation and a low emission of thermal radiation. In order to make a maximum use of incident solar energy, the absorber's surface is covered with selective layers that increase the energy efficiency by a better heat conduction [14].

The knowledge described in the introductory part of the system enables the application in the field of thermal collectors which utilize tracking constructions enabling collectors rotation so that they can capture the maximum amount of solar energy. Technical involvement of a collector system with rotation has been implemented in the multivalent laboratory of the Department of Process Technique. The involvement system as well as the control system is described in the following section of the paper. The aim of the carried out experiments was the verification of the knowledge and its application in practice, while the important role plays the efficiency evaluation in the period with a relatively short time of sunshine. The utilisation of the rotary system as the possibility of the stagnation elimination of the systems with solar collectors has also been verified. Thermal stagnation of the system is the state where the accumulation tanks no longer are able to take more thermal energy which leads to the system overheating. In order to verify the efficiency of the rotary system, in connection with the elimination of the system stagnation, a separate experiment was conducted. Such a condition is undesirable for solar systems because it results in thermocompressive stress of the individual parts of the system [15]. With modern solar thermal systems, there exists the potential to reach very high temperatures during high solar irradiance conditions. Even mid-temperature flatplate solar collectors may reach temperatures in excess of $180^{\circ} \mathrm{C}$ during no-flow conditions caused by power or equipment failures or during routine shutdowns when there is a reduced energy demand. During these periods, referred to as stagnation conditions, there is the potential to seriously damage solar collectors or system components, accelerate the degradation of materials and heat transfer fluids, and even lead to user scalding. While the latter may be controlled by mixing valves, loss of performance and system degradation is more difficult to control $[16,17]$.

1.1. The Interaction between the Earth and the Sun in relation to the Solar Radiation Incident. In relation to the definition of the solar radiation intensity, it is necessary to consider the declination, which is given by the Earth's tilt in relation to the direction of sunrays.

During the year this change of declination represents the interval between $+23.45^{\circ}$ (June 22) and $-23.45^{\circ}$ (December 22) $[3,9,18]$. The declination can be determined by the relation $[7,9]$ :

$$
\delta=23.45 \cdot \sin \left[360 \cdot \frac{284+n}{365}\right]\left(^{\circ}\right),
$$

where $\delta$ is the solar declination and $n$ is the day of the year.

The solar declination varies; for each day of the year it has a different value $[10,18]$. The most common calculations take into account the only representative declination value for each month. It is the declination of the so-called characteristic day of the month for which the parameters determining the position of the Sun above the horizon and the radiation intensity are calculated [10]. The diagram and the parameters of the solar radiation intensity calculation are shown in Figure 2.

A mutual position of the Sun and the irradiated surface changes; it is given by the height of the Sun above the horizon and its azimuth [18] (by the diversion from the north-south axis) whereas the following equation is applied [8] as follows:

$$
\sin (h)=\sin \delta \cdot \sin \varphi+\cos \delta \cdot \cos \varphi \cdot \cos \tau,
$$

where $h$ is the height of the Sun above the horizon, $\delta$ is the Sun's declination, $\varphi$ is a latitude (Prešov $49^{\circ}$ ), $a$ is the azimuth of the Sun, and $\tau$ is the time angle.

\subsection{The Calculation of the Amount of the Incident Solar Energy} for a Perpendicular and a Universal Area. The amount of solar energy falling on the Earth's surface is affected by the Earth's rotation and the tilt of the Earth's axis to the ecliptic. The average intensity of the sunlight decreases with the increasing latitude and it also depends on local climatic conditions $[18,19]$.

The solar radiation falling on the outer surface of the atmosphere is in an unscattered form; while passing through the atmosphere, it becomes scattered. The solar radiation weakens when passing through the atmosphere' a part of the radiation is reflected, another part is absorbed, and the rest of it is scattered and reflected in the atmosphere $[6,10,20-22]$. Approximately $50 \%$ of the original solar radiation falls on the Earth's surface. A part of the solar radiation is scattered in the form of a diffuse solar radiation which loses a directional nature; it is active in all directions with the same intensity $[6,23,24]$. A diffuse radiation is a result of the scattering of a direct solar radiation by atoms, molecules in the atmosphere, and aerosols dispersed in the air [6,21]. A reflected radiation 


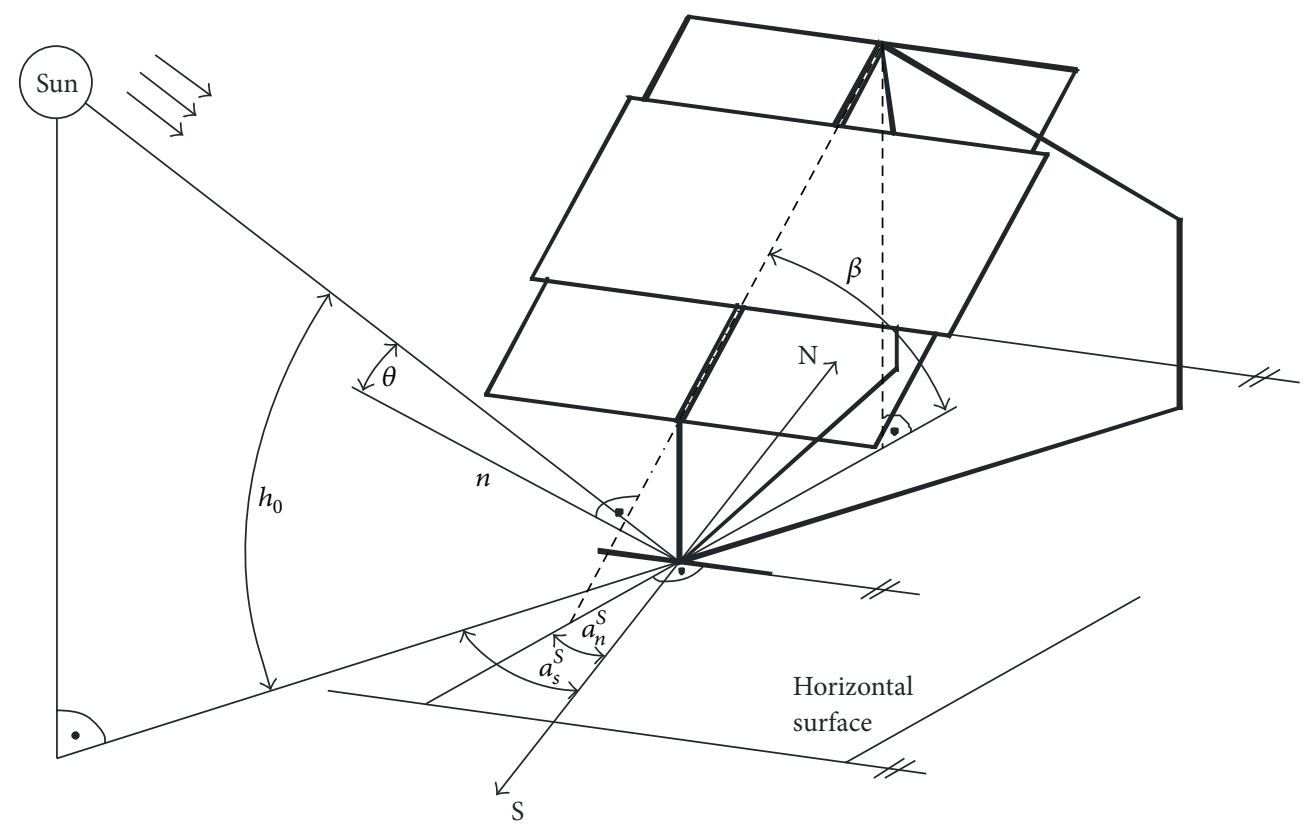

FIGURE 2: A diagram of solar radiation incident on a universal area $[3,4,8]$. S, N-cardinal points, $h_{0}$ - height of the Sun, $\theta$-the angle between a surface normal and sunbeams, $\beta$-a tilt angle of collectors area from a horizontal plane, $a_{n}^{S}$-azimuth of the normal from the south, and $a_{s}^{S}$ - the azimuth of the Sun from the south.

from the surrounding surfaces and terrain also contributes to the diffuse radiation [25].

The final phase of all energy transformations of solar radiation is the heat, which is reemitted as infrared radiation. A direct solar radiation has a significantly direct directional character. In terms of a wavelength, a direct solar radiation is characterized by the wavelength within the interval $\lambda=$ $300-3000 \mathrm{~nm}$. A diffuse radiation reaches wavelengths in the range $\lambda=6000-30000 \mathrm{~nm}[3,25]$.

A total solar irradiance $G_{t}$ is the sum of a direct horizontal irradiance $G_{b}$, a diffuse irradiance $G_{d}$, and a reflected irradiance $G_{r}$. The sum of a direct and diffuse irradiance incident on a horizontal surface forms a global irradiance $[3,4,8,26,27]$.

Global irradiance $(G)$ is the sum of the direct horizontal and diffuse components, given as [27]

$$
\begin{gathered}
G=G_{b}+G_{d}\left(\mathrm{~W} \cdot \mathrm{m}^{-2}\right), \\
G_{b}=G_{n} \cos \theta_{z},
\end{gathered}
$$

where $G_{b}$ is direct horizontal irradiance and $\theta_{z}$ is zenith angle.

The total irradiance is then expressed by the relation

$$
G_{t}=G_{n} \cos \theta+G_{d}+G_{r}\left(\mathrm{~W} \cdot \mathrm{m}^{-2}\right) .
$$

According to $[3,10,25]$, a solar constant $I_{0}\left(\mathrm{~W} \cdot \mathrm{m}^{-2}\right)$ is the energy flow to the outer edge of the atmosphere, which can be expressed as follows:

$$
I_{0}=1367\left(1+\frac{\cos (29.7 M+0.98 D-32)}{30}\right)\left(\mathrm{W} \cdot \mathrm{m}^{-2}\right) \text {. }
$$

The amount of intensity of solar energy incident on the Earth's surface can be determined by

$$
I_{b n}=I_{0} \cdot A^{-T_{L}}
$$

where $I_{b n}$ is the intensity of a radiation perpendicularly striking the surface, a direct radiation, $I_{0}$ is a solar constant $\left(\mathrm{W} \cdot \mathrm{m}^{-2}\right), A$ is the coefficient depending on the height of the Sun above the horizon, and $T_{L}$ is the coefficient of atmospheric pollution; this value varies from a minimum in winter to a maximum in summer $\langle 2,8\rangle$.

To determine the intensity of a direct radiation upon a surface, the following is applied [3]:

$$
I_{b}=I_{b n} \cdot \cos \theta \text {, }
$$

where $\theta\left(^{\circ}\right)$ is the angle between a surface normal and sunbeams.

A diffuse component of the radiation incident on a horizontal plane can be expressed according to [3] as follows:

$$
\begin{aligned}
I_{d h}= & \left(I_{\theta} \cdot \sin h_{\theta}-\frac{I_{b} \cdot \sin h_{0}}{\cos \theta}\right) \\
& \cdot\left(0,25+0,025 T_{L}\right)\left(\mathrm{W} \cdot \mathrm{m}^{-2}\right) .
\end{aligned}
$$

Using the equation for a diffuse radiation falling upon a horizontal plane, it is possible to calculate the size of this component of radiation striking an arbitrarily tilted surface [3]:

$$
I_{d}=\frac{I_{d h}}{2}\left[1+\cos \beta+\left(0,94 \cdot e \cos \theta+\frac{1,84}{T_{L}}\right) \cdot \cos \beta\right]
$$

$\left(\mathrm{W} \cdot \mathrm{m}^{-2}\right)$. 


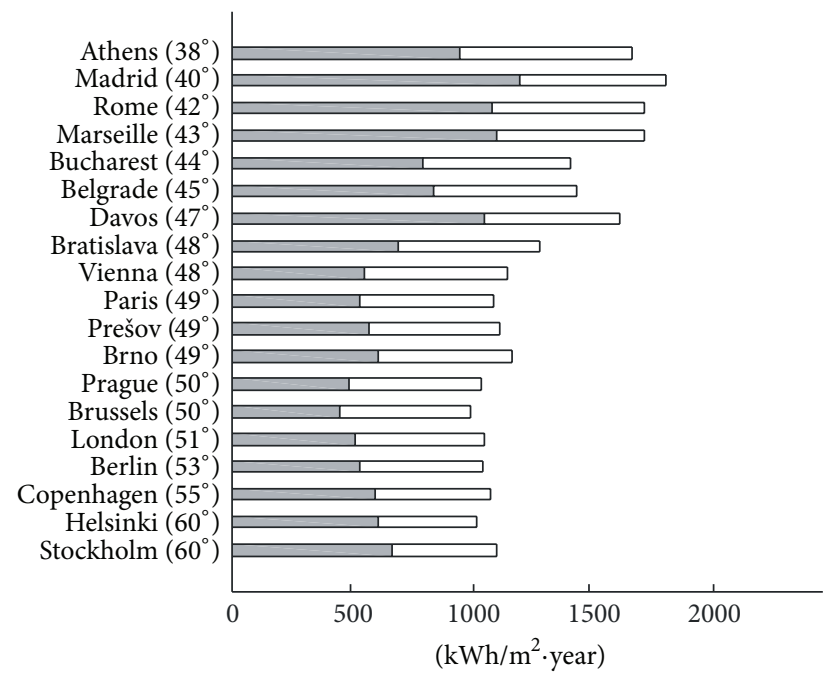

FIgURE 3: The ratio of a direct (dark) and diffuse (light) solar radiation during a year for the selected cities in Europe [25].

For the reflected radiation, the following relation holds:

$$
I_{r}=0,5 \rho(1-\cos \beta) \cdot\left(\frac{I_{0} \sin h_{\gamma}}{\cos \theta}+I_{d h}\right)\left(\mathrm{W} \cdot \mathrm{m}^{-2}\right),
$$

where $\rho$ is a reflectivity $(-)\langle 0.15 ; 0.9\rangle$.

1.3. The Utilisation of Solar Radiation Energy in Central Europe. For an effective utilization of solar radiation energy in heliotechnique, detailed data on solar radiation incident on the Earth's surface are required [19, 20,28]. Figure 3 shows the cumulative values of a proportion of a direct and diffuse solar radiation throughout the year on a perpendicular unit area for the selected areas of Europe.

As shown in the graph, in the interval of latitude $38^{\circ}$ to $60^{\circ}$ (Figure 3), the amount of incident energy is in a relatively narrow interval, that is, in the range from about $1000 \mathrm{kWh} / \mathrm{m}^{2} /$ year to $1300 \mathrm{kWh} / \mathrm{m}^{2} /$ year.

If the azimuth deviation of the irradiated surface does not exceed $45^{\circ}$, the annual amount of incident energy does not vary by more than $10 \%$ (Figure 4 ). The increasing angle of deviation above $45^{\circ}$ results in a significant decrease in the amount of the incident energy by more than $20 \%$ [25].

According to [25], the optimum tilt of the irradiated area, when taking into account the highest total incident energy, in terms of latitude 49 , is $35^{\circ}$. Taking into consideration a fullyear gain of solar energy, the tilt angle is in the range of $40^{\circ}-$ $50^{\circ}$.

\section{Materials and Methods}

2.1. The Preparation of Experimental Measurements. To assess the use of solar radiation energy, an experiment has been designed and implemented whose essence was to investigate the effect of a thermal collector system rotation on the amount of gained thermal energy. The experiment included the development of methodology for the calculation of the

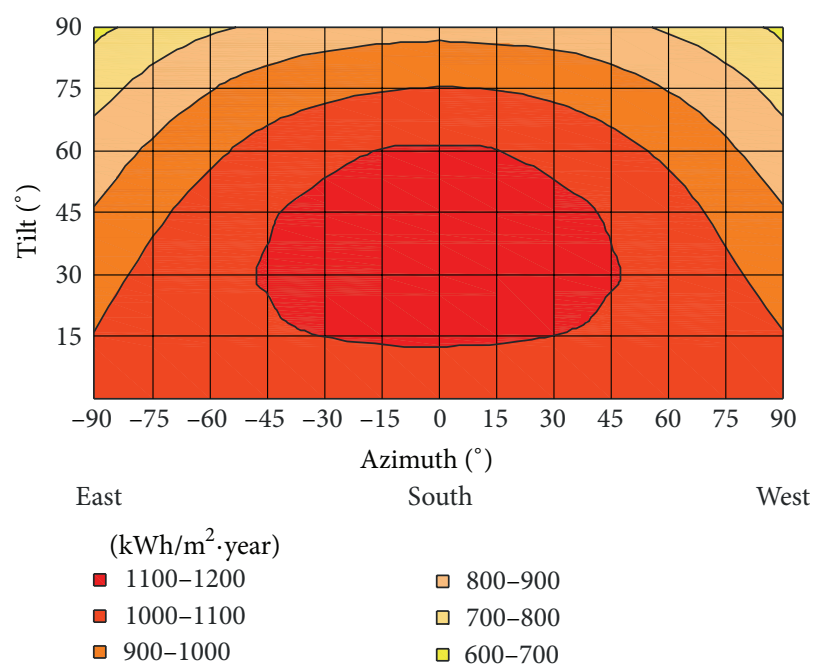

FIGURE 4: Dependence of the amount of energy incident per unit area on the tilt and azimuth [25].

gained energy at the reference level, which was represented by the amount of energy obtained without a collector system rotation, the so called static system. The algorithm of the experimental measurements has been implemented according to the following diagram (Figure 5).

2.2. The Characteristics of a Thermal System. The experimental measurements were carried out based on a solar thermal system located in the premises of the Department of Process Technique. The diagram of the system utilised in the experiments is shown in Figure 6. It consists of four flat-plate solar panels HERZ CS 100F installed on a tracking steely-zinc construction which rotates following the ecliptic (Figure 7). The device comprises a system of the construction control, pumps group, safety devices, accumulation tanks, a three-way diverter valve with an actuator, and a fluidic flowmeter with a calorimetric calculator. The active area of the collector is $7.56 \mathrm{~m}^{2}$.

The thermal energy of the system is transmitted in the tank for a domestic hot water (DHW) heating VT-S 1000 FRMR having the volume of $970 \mathrm{~L}$ and in the tank for water heating PSR800 having the volume of $800 \mathrm{~L}$. Both tanks have temperature resistance sensors placed in stepped horizontal layers so that it is possible to sense the distribution of the fluid temperature in the tank.

The control system allows adjusting the circulation pump so that the pump can be activated after reaching a higher temperature of a medium in the collector than the temperature of the medium in the tanks. And, vice versa, when the temperature falls below that of the medium in the tanks, the pump is deactivated.

A three-way diverter valve allows switching between the mentioned accumulation tanks. The control system compares the temperatures of water in the tanks and the tank, in which the fluid temperature is lower, is recharged. This provides a more favourable temperature drop and proportionately a more efficient transfer of thermal energy of the heat 


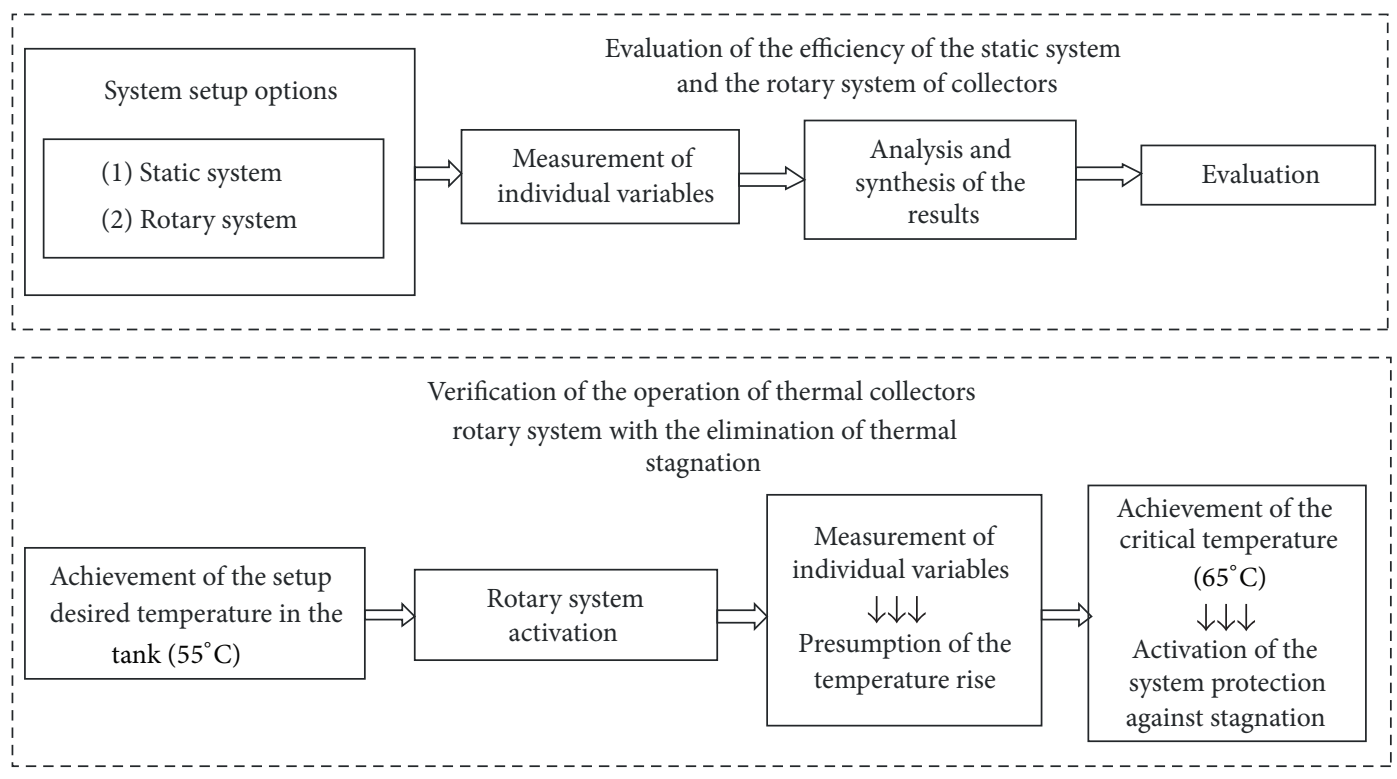

Figure 5: Flow diagram of the experimental measurements.

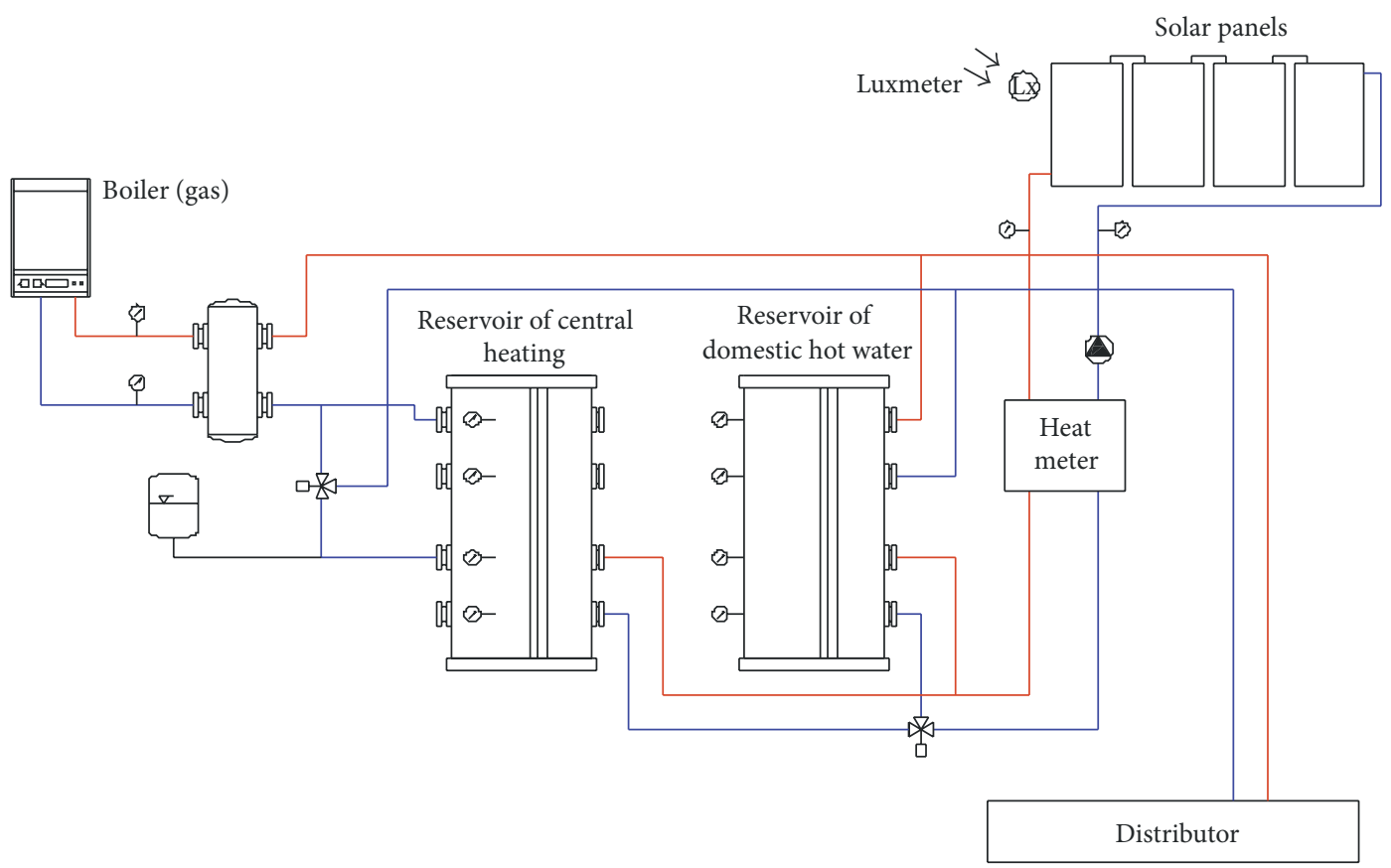

FIgURE 6: A diagram of a part of a multivalent laboratory system used in the experiments.

transfer fluid to the tank. If the temperature approaches the temperature of the heat transfer fluid, the efficient transfer of thermal energy does not occur and the system is switched to the other tank.

2.3. Thermal Tracking System Control. A control system used in the implementation of the experiment comprises three levels: the pump system control system, the solar system protection, and the system of rotation.

The diagram shown in Figure 8 [29-31] illustrates the pumps control and the solar system protection. The pump operation is conditional upon the achievement of the defined difference of the measured temperature values at the output of the solar panels and the temperature values in the accumulation tanks. The temperature difference is determined to be $5^{\circ} \mathrm{C}$.

The system measures the current intensity of solar radiation and if the value exceeds $40 \mathrm{klx}$, the circulation pump is activated. The pump system control also serves to protect the solar panels against overheating. The pump operation is activated by a pulse cyclic generation in the range of 1 minute at regular intervals of 15 minutes. When the intensity of the 


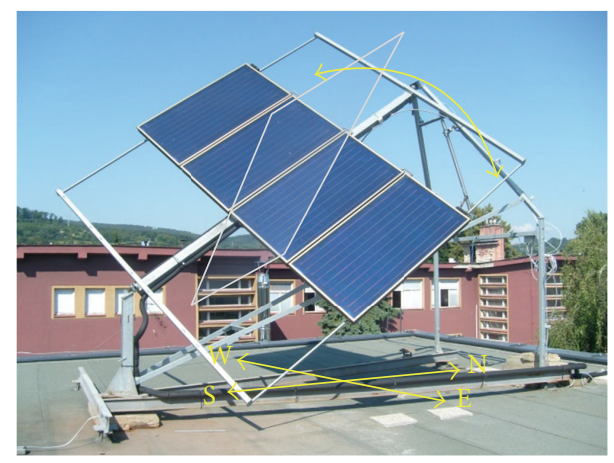

FIGURE 7: Solar panels installed on a rotary tracking construction copying the path of the Sun.

radiation drops below $10 \mathrm{klx}$, the operation of the circulation pump is shut down.

When determining the critical values, knowledge of thermal systems control was applied while using thermal hysteresis. It is necessary to achieve a sufficient energy accumulation in the collectors. After reaching a temperature difference of $5^{\circ} \mathrm{C}$, the energy gain of panels is usually sufficient for a continuous operation. The value of $40 \mathrm{klx}$ was determined empirically. With the values below $40 \mathrm{klx}$, the required energy gain was not achieved.

The thermal system overheating protection (Figure 9) operates with a preventive effect against damage due to high temperatures. If the output temperature of the solar system rises above a defined maximum value $\left(60^{\circ} \mathrm{C}\right)$, the circulation pump is activated. The heat discharged from the solar cells is accumulated in storage tanks.

If the accumulation tanks are no longer able to take more of the heat energy, the protection system via a circulation pump becomes ineffective. The panels are automatically turned so as to minimize the irradiated area.

A block diagram in Figure 10 [29, 32-34] shows a control system of the rotation of the solar panels construction. In the case of achieving the desired value of the solar radiation intensity, the system activates the operation of a linear motor [35-37]. The control system calculates the exact position of the Sun based on the specified object location using the GPS coordinates, local time, and a current date (Figure 11).

Since the collectors rotation is carried out around one axis, the azimuth extrapolation is used. It is extrapolated by a linear transducer to the required position within the range of 0 to 100 , which is sent to the block controlling and linear motor of the construction with the solar panels. The required radiation intensity to start a rotation is set to the value of $30 \mathrm{klx}$. The value of radiation intensity to start the rotary system is determined empirically. It represents the value above which there is a relative generation of energy gain while rotation enables maximizing the system efficiency. The rotary system will stop when the intensity drops to $10 \mathrm{klx}$. When the value drops below $10 \mathrm{klx}$, the amount of incident solar energy is minimum and a subsequent energy gain of collectors is minimized. In such a case it is not required that the tracking construction rotates. The rotation is restored after the intensity of solar radiation is reincreased above the value of $30 \mathrm{klx}$, while the position of the tracking construction is directed towards the actual Sun's position.

The position control (Figure 12) [29,37-41] is carried out in the regime with three levels Open, Close, and Stop. In this case, it refers to the rotation to the right, to the left, and stop. The appropriate form of the signal is determined based on the evaluation of the radiation intensity. If the radiation intensity is sufficient, the construction rotation is provided according to the current calculated position of the Sun. In case of the intensity drop below a critical value of the radiation intensity, the motor stops. The motor subsequently starts operating after the rise in radiation intensity. The value of radiation intensity to start the motor of a rotary system is set to $30 \mathrm{klx}$. To prevent from the excessive turning of the construction, the end sensors are positioned in the end positions (Figure 13), which also serve as zero points for the calculation of the end positions in the interval 0-100. The endpoints are the starting and end positions of a panel while rotating along the path copying the movement of the Sun. After reaching the end position, the panel remains in a given position. After sunset, the motor of a panel is activated and returns the panel to the central position so that the panel normal is parallel to the normal of the roof plane. This position is the best in terms of adverse weather, especially wind. This eliminates the side effect of wind that would be manifested in one of the end positions. This function is purely precautionary. Before sunrise, the motor is again activated directing the panel to the starting position.

The process levels of control, monitoring, and data collection are provided by a software system based on Siemens Desigo Insight (Figure 14).

2.4. The Conditions of the Experiment. The experiment was conducted during the spring equinox (vernal equinox). During the monitored period, the proportion of sunshine hours in relation to the maximum in the summer period of solstitium (summer solstice) is $74.25 \%$. The basic conditions during the experiment as well as the characteristics of the position in terms of the laboratory location are shown in Table 1.

The laboratory of the Department of Process Technique of the Technical University in Košice is located in the territory of the city of Prešov (Slovakia). As for the climatic conditions, the city is located in the northern temperate zone characterized by four seasons.

The region of Prešov falls within the moderately warm area where the average annual temperature is in the range of $4^{\circ} \mathrm{C}$ to $8^{\circ} \mathrm{C}$. Wind conditions are complicated not only due to the complicated orography (the Earth's relief) but it is also greatly influenced by a considerable variability in weather throughout the year [42].

The annual average wind speed is within the range of 2 to $3 \mathrm{~m} \cdot \mathrm{s}^{-1}$. Regarding the rainfall, during the summer period (June-August) it is about $40 \%$, in the spring it is $25 \%$, in the autumn it is $20 \%$, and it is $15 \%$ in winter (a high predominance of rainfall in the summer). The rainiest month is usually June 


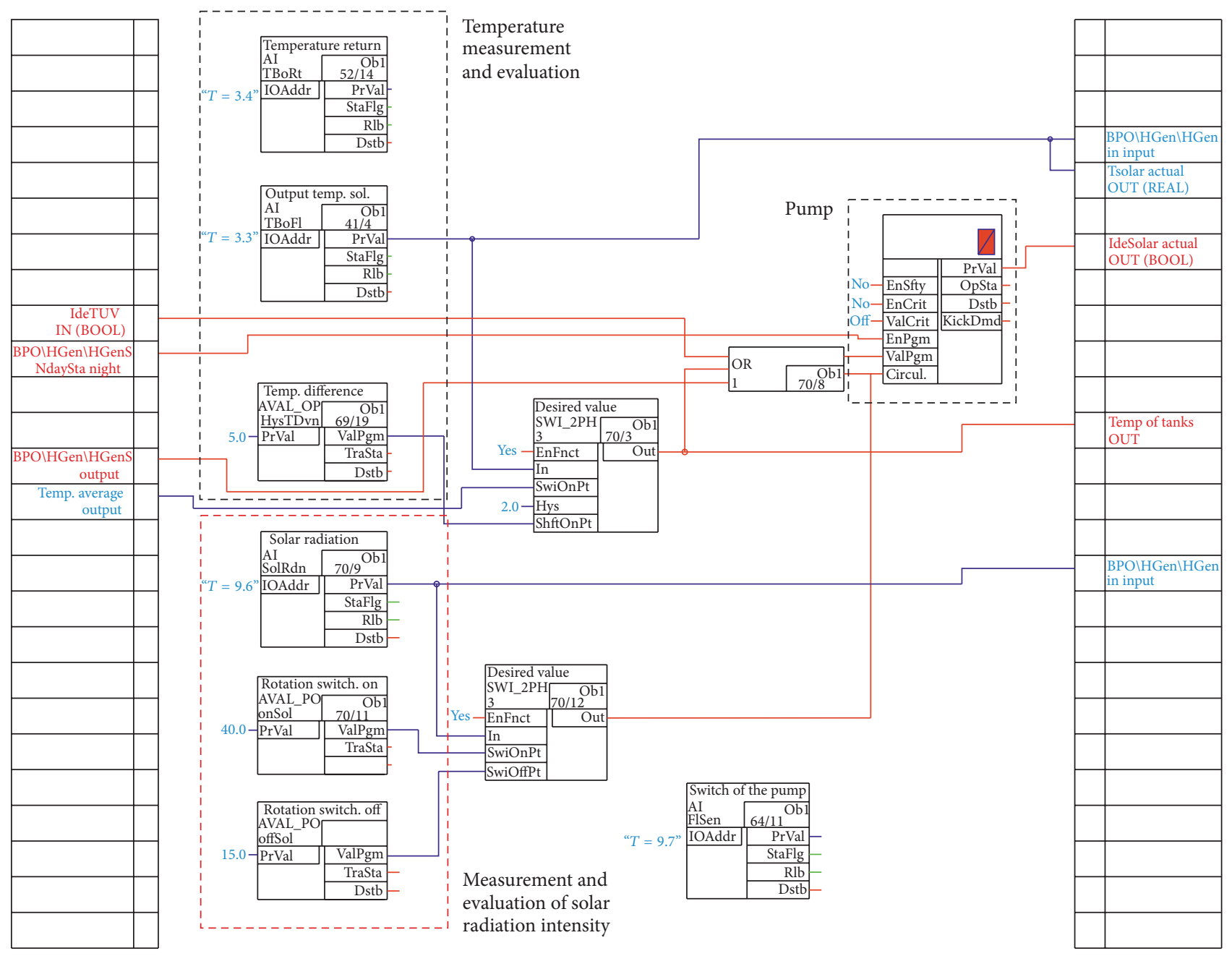

Figure 8: A diagram of the pump system control.

TABLE 1: The conditions during the experiment implementation.

Coordinates of the laboratory

Elevation

Declination of the Sun*

Angular height of the Sun**

The ambient temperature during sunshine, a tracking system

The ambient temperature during sunshine, a static system

The average ambient temperature during sunshine, a tracking system

The average ambient temperature during sunshine, a static system

Interior temperature during sunshine, a tracking system

Interior temperature during sunshine, a static system

The average temperature inside the laboratory during sunshine, a tracking system

The average interior temperature of the laboratory during sunshine, a static system

Static system

Rotation

In the monitored period and ${ }^{* *}$ at noon. $48^{\circ} 59^{\prime} 07.3^{\prime \prime} \mathrm{N} 21^{\circ} 14^{\prime} 27.6^{\prime \prime} \mathrm{E}$

$296 \mathrm{~m}$

$\left\langle-0.81^{\circ} ; 4.81^{\circ}\right\rangle$

$\left\langle 40.08^{\circ} ; 45.60^{\circ}\right\rangle$

$\left\langle 11.81^{\circ} \mathrm{C} ; 15.57^{\circ} \mathrm{C}\right\rangle$

$\left\langle 11.28^{\circ} \mathrm{C} ; 14.58^{\circ} \mathrm{C}\right\rangle$

$14.57^{\circ} \mathrm{C}$

$13.14^{\circ} \mathrm{C}$

$\left\langle 23.57^{\circ} \mathrm{C} ; 25.17^{\circ} \mathrm{C}\right\rangle$

$\left\langle 21.87^{\circ} \mathrm{C} ; 23.85^{\circ} \mathrm{C}\right\rangle$

$24.67^{\circ} \mathrm{C}$

$22.45^{\circ} \mathrm{C}$

$\langle 26.3 .2014 ; 1.4 .2014\rangle$

$\langle 20.3 .2014 ; 24.3 .2014\rangle$ and $\langle 2.4 .2014 ; 3.4 .2014\rangle$ 


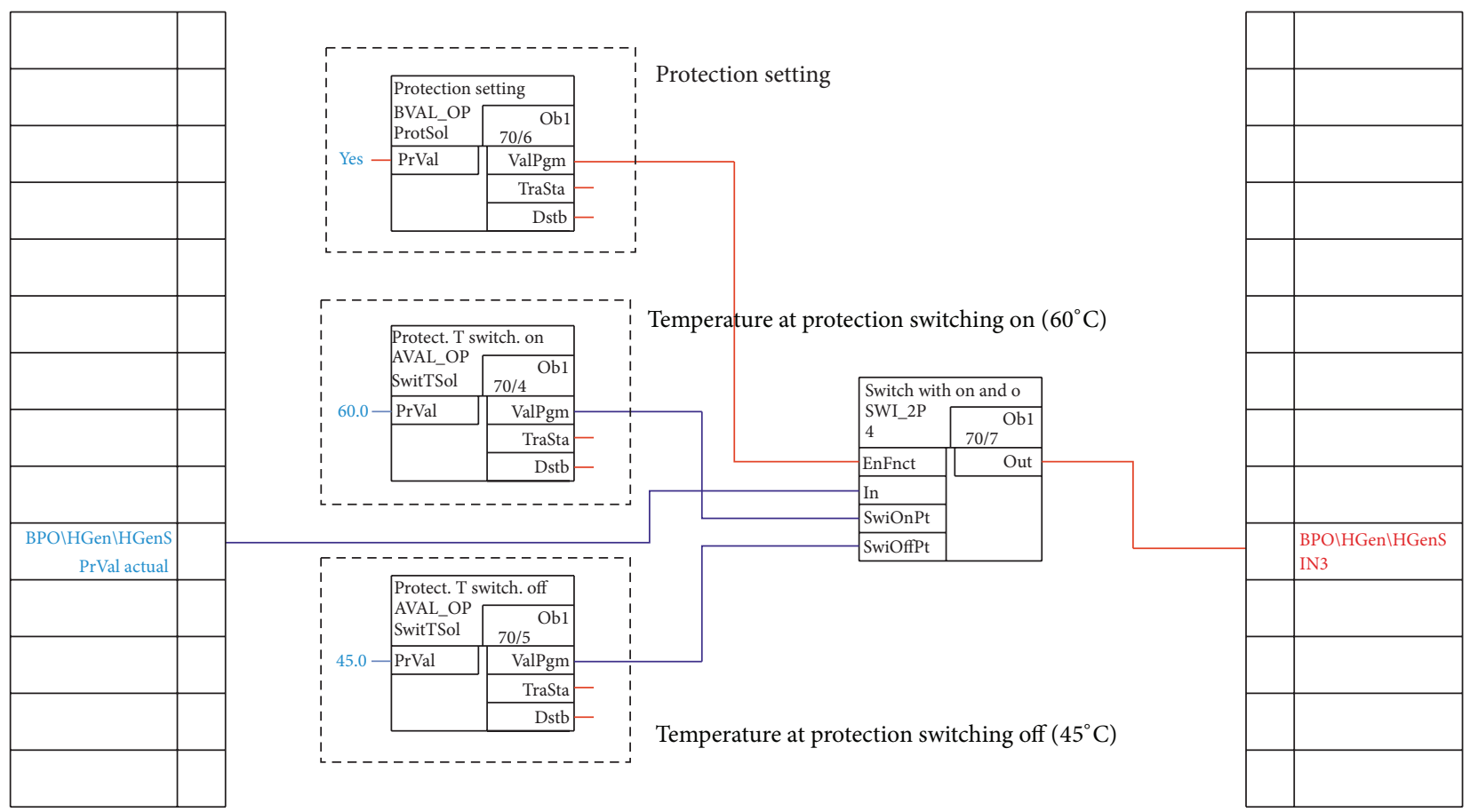

FIGURE 9: A diagram of protection against overheating.

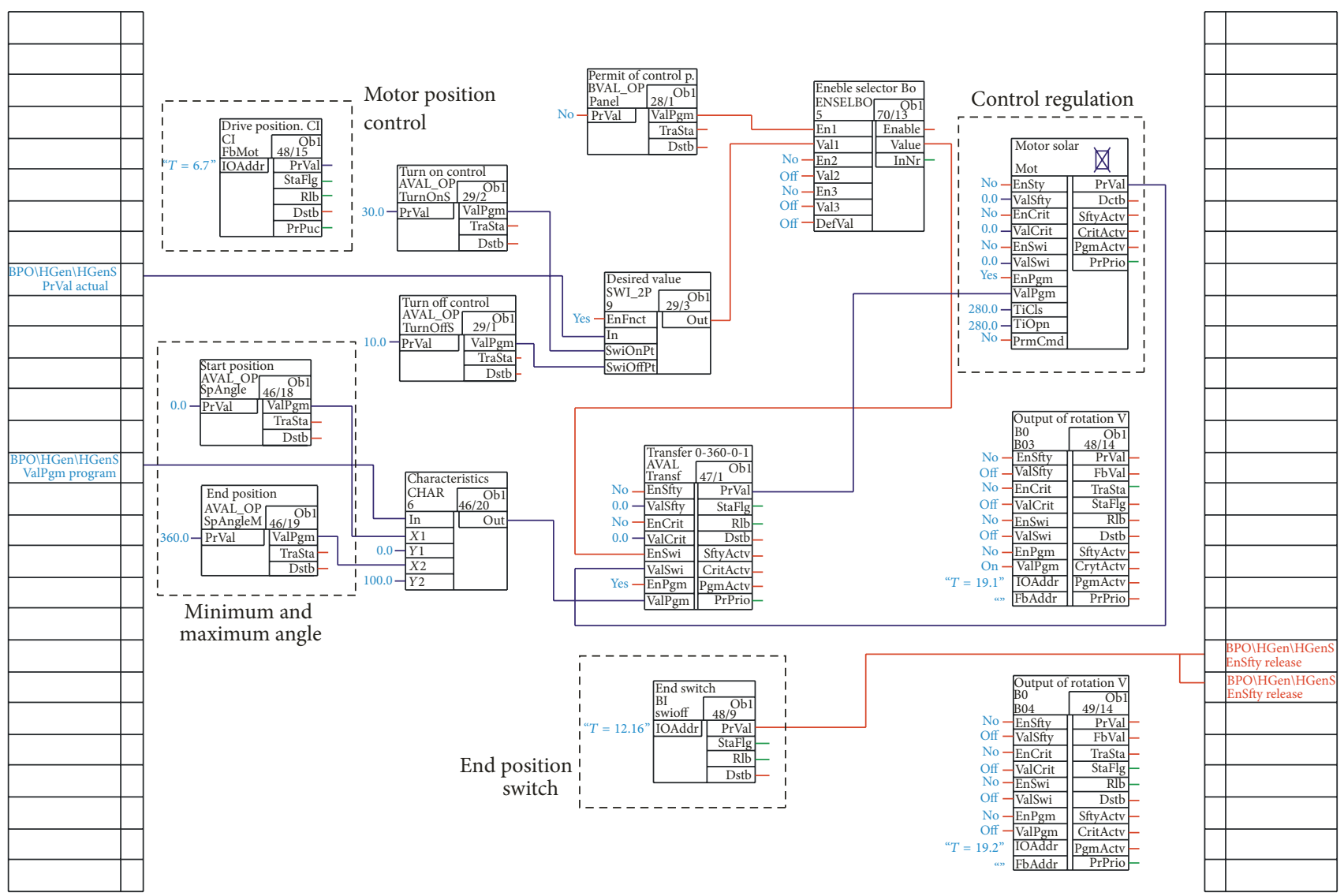

FIGURE 10: A block diagram of a control system of a construction rotation. 


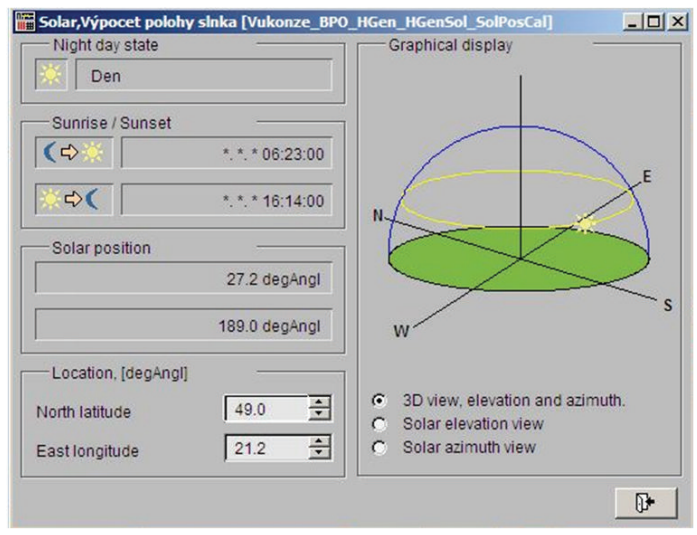

FIGURE 11: Parameters setting on the screen of the calculation of the Sun position.
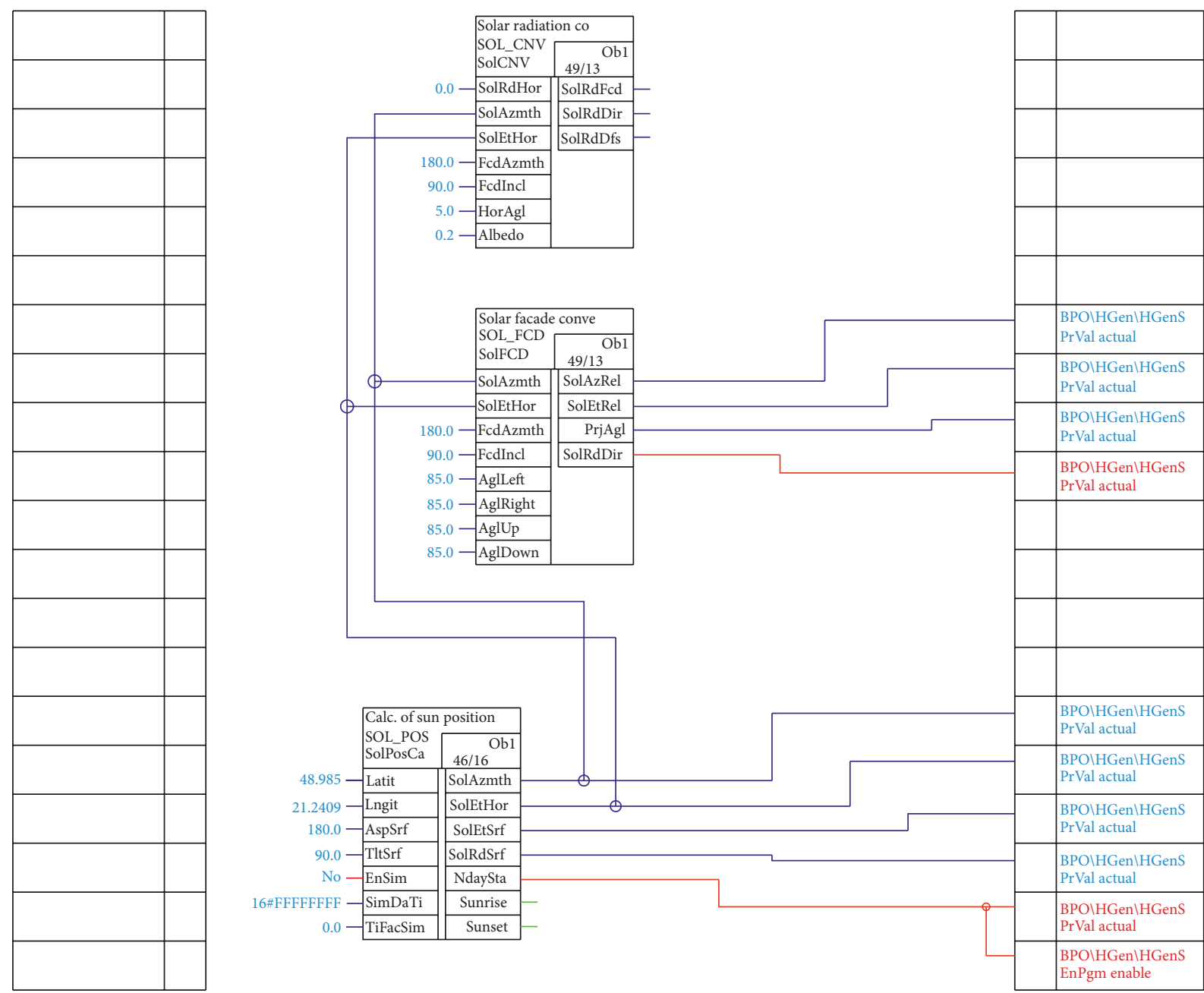

FIGURE 12: A block diagram of the Sun position calculation.

or July, and the minimum rainfall is between January and March. In winter, much of the precipitation falls as snow [42].

The maps in Figure 15 show average monthly temperatures during the experiment conducted in March and April. Figure 16 shows the maps of the deviations of the average monthly air temperature from a long-term average. The temperatures in March and April show an increase above average values of temperature compared to a long-term average temperature for the given season. In March, these temperatures exceeded the mean values by $4.5^{\circ} \mathrm{C}$. In April, the 

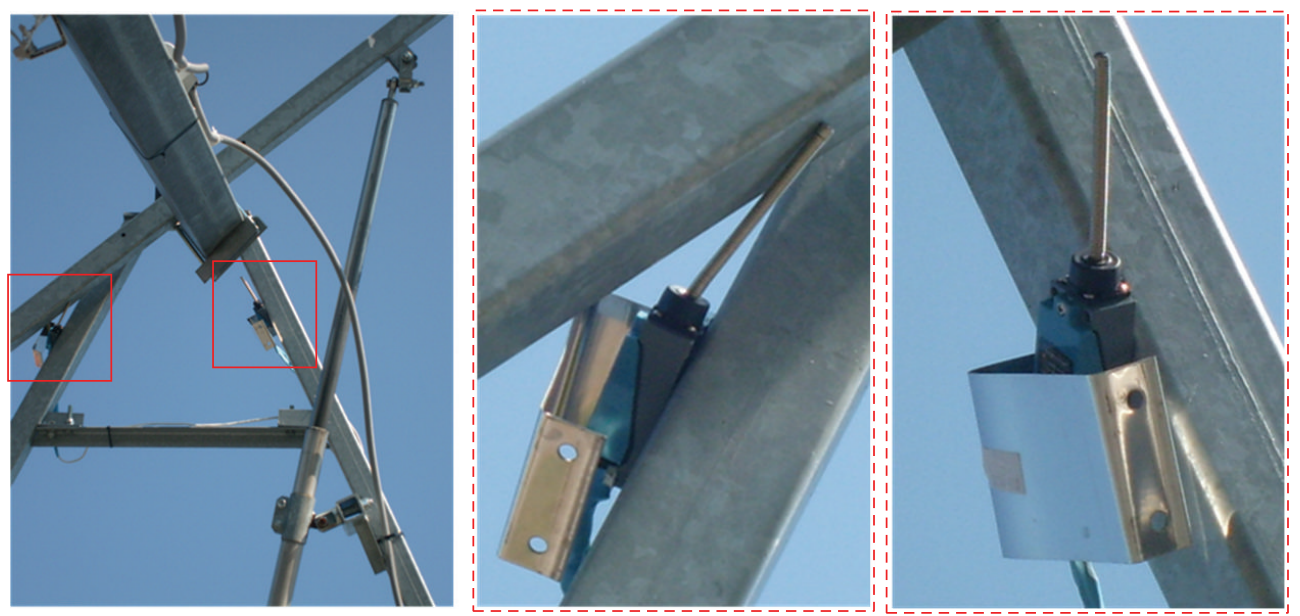

FIGURE 13: Location of the end sensors on the construction.

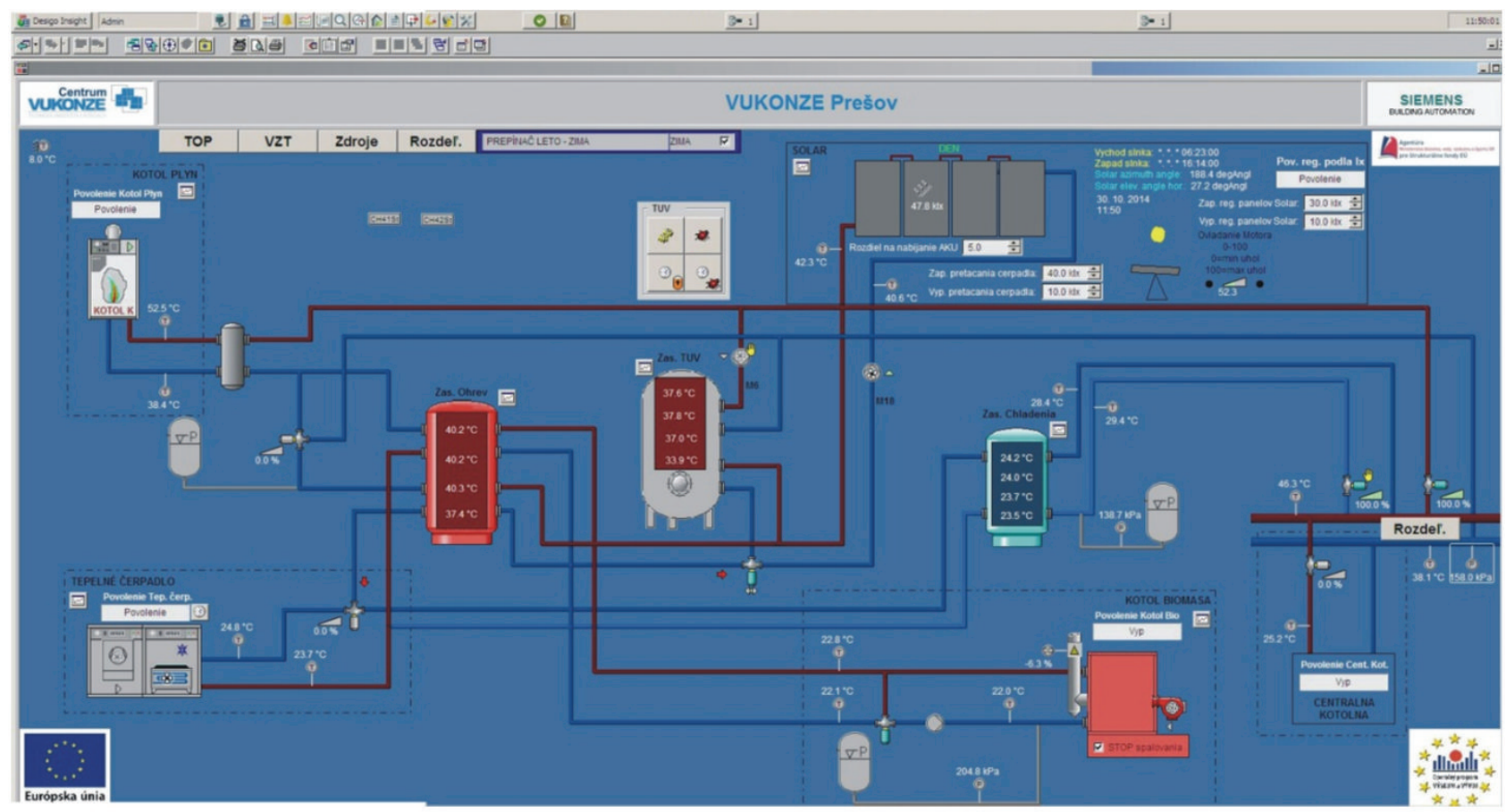

FIGURE 14: The screen of the control system.

difference was reduced to $1.8-2.3^{\circ} \mathrm{C}$. These increased values have not a significant impact on the conducted experiments. Possible differences would be manifested in the possible interannual comparison.

In terms of changes in the tilt angle of thermal panels in relation to the position of the Sun in the course of the experiments, there was a change in the range $40.08^{\circ}-45.6^{\circ}$ for 12 oclock of local time. The changed angle represents the value of about $5.5^{\circ}$, which has no significant effect on the amount of the gained energy. Regarding the tilt requirement for the experiments implementation based on theoretical knowledge [4], the tilt of $45 \%$ for the monitored period seems to be most advantageous. Considering a full-year term, the angle change, however, has a significant impact, especially on a fixed solar system.

\section{Results}

The results of the measurements are illustrated in the graphs showing courses of temperatures in tanks, the intensity of solar radiation, the dependence of the produced energy on the intensity of solar radiation, temperature changes in the output of solar collectors, ambient temperature, the time of sunrise and sunset, and the beginning and the end of energy conversion. The graphs of Figures $17(\mathrm{a})-17(\mathrm{~g})$ show the daily courses of the individual monitored values for the static 


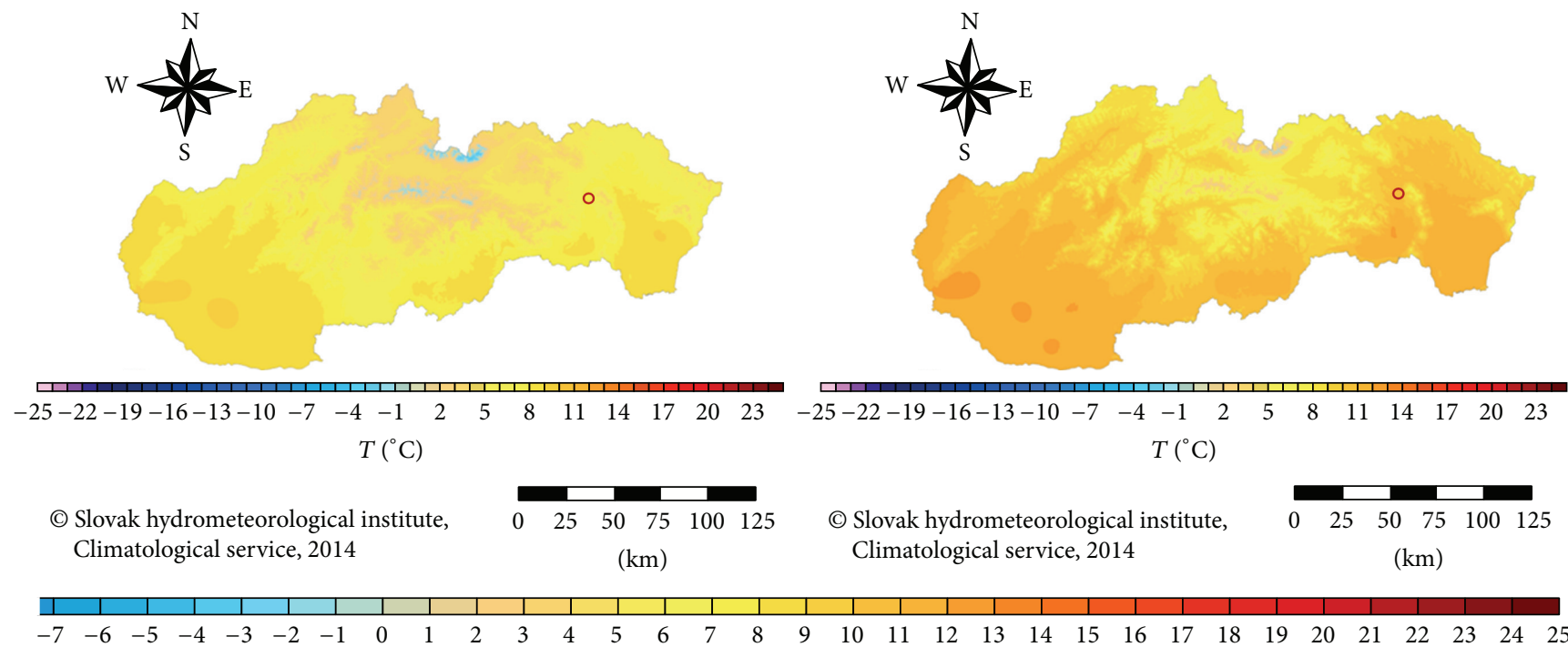

FIGURE 15: The average monthly air temperature in March/April 2014 [42] (according to the Slovak Hydrometeorological Institute).
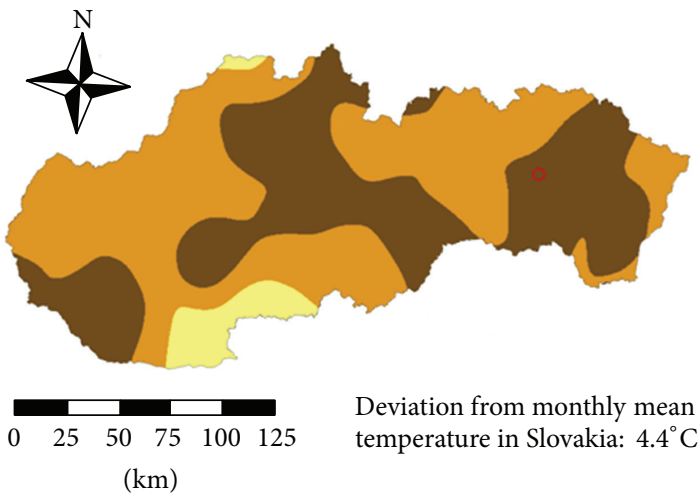

Deviation from monthly mean air temperature in Slovakia: $4.4^{\circ} \mathrm{C}$ $(\mathrm{km})$

(C) Slovak hydrometeorological institute, Climatological service, 2014

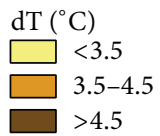

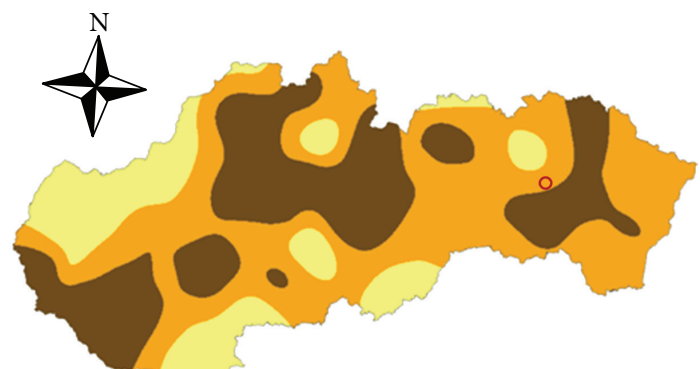

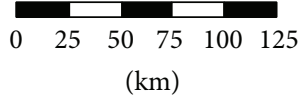

Deviation from monthly mean air temperature in Slovakia: $4.4^{\circ} \mathrm{C}$

(C) Slovak hydrometeorological institute, Climatological service, 2014

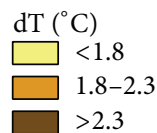

FIGURE 16: Deviations of the average monthly air temperatures from the normal in March/April 2014 [42] (according to the Slovak Hydrometeorological Institute).

system. The outputs of the system with rotation are shown in Figures 17(h)-17(n).

Based on the behaviour of the individual graphs in Figure 17, it is possible to observe the relation between the intensity of radiation and the temperature at the output of the collectors as well as the amount of the energy gained. With a significant fluctuation in the intensity, Figure 17(a), the amount of the gained energy is relatively small with both the fixed system and the rotary system, Figure $17(\mathrm{k})$, eventually Figure 17(l). On the contrary, almost ideal course of intensity (a bright day without clouds) can be observed in the case of Figure 17(e) for the fixed system and Figure 17(i) for the system with a rotary collector. Comparing the two graphs courses, it can be demonstrated that even when lighting and weather conditions are the same, the energy is gained more efficiently with the rotary system. With the rotary system, an increase in temperature at the output of the collectors above the reference level occurs significantly earlier (at 7:05 a.m. CET) and the temperature drops at 3:35 p.m. In the case of the fixed system, the temperature increase occurs one hour later (7:55 a.m. CET) and a drop occurs at 3:00pm. The length of time before the rotary system is capable of producing energy under approximately the same conditions of the radiation intensity is about 8.5 hours. The fixed system generates the energy gain during 7 hours of operation. However, the advantages of the earlier morning rise are partly eliminated by lower outdoor temperatures characteristic for this season of the year (see Figures 17(a)-17(n)). The afternoon extension 


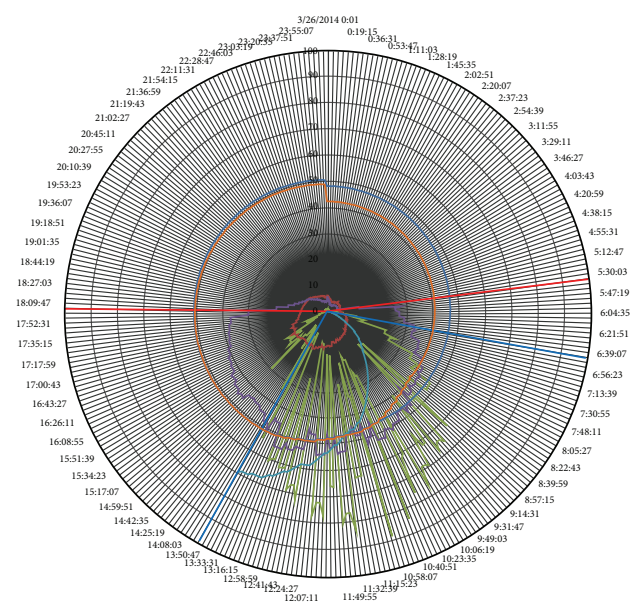

(a)

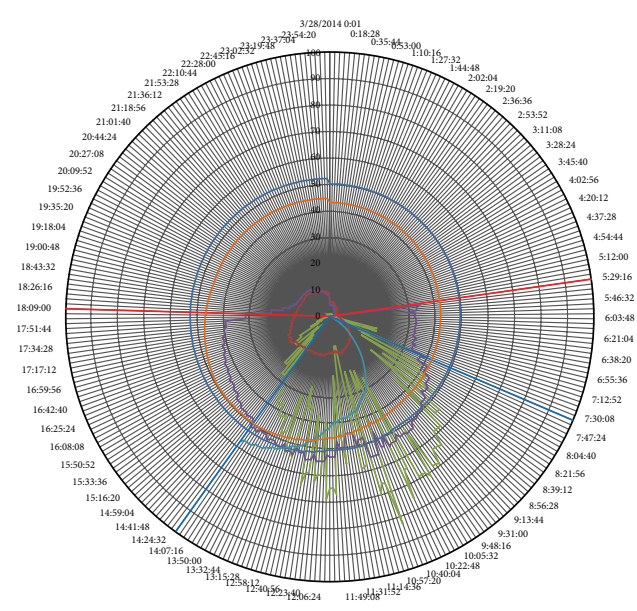

(c)

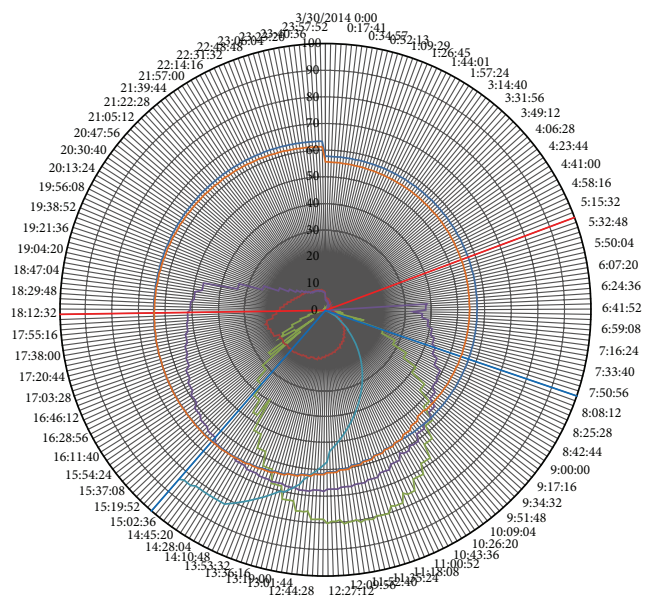

- Sunrise and sunset

_ Beginning and end of energy production in the system

- Gained energy

_ Intensity of solar radiation

- Outdoor temperature

- Temperature in the output of the collectors

_ Temperature inside storage tank I

— Temperature inside storage tank II

(e)

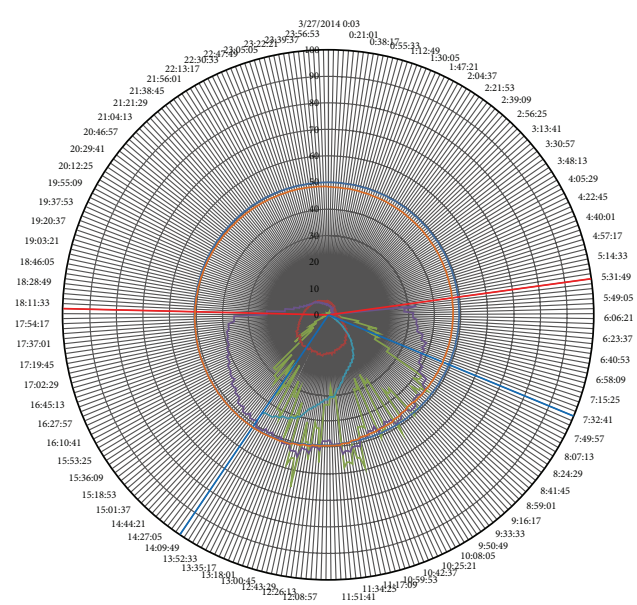

(b)

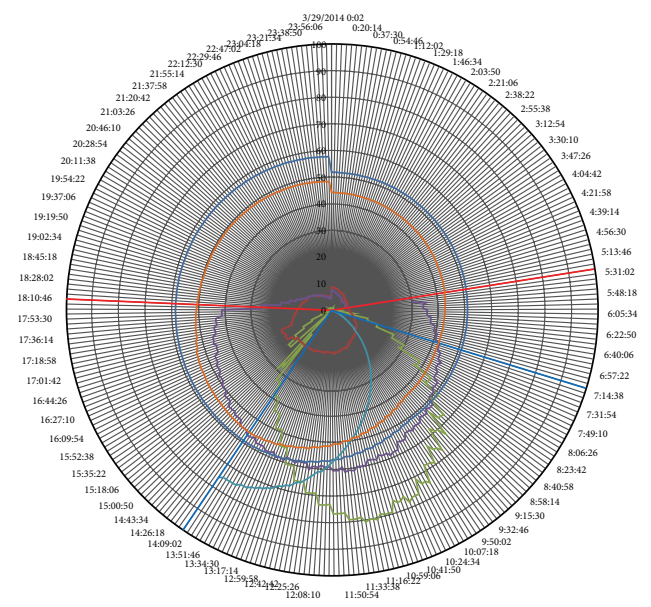

(d)

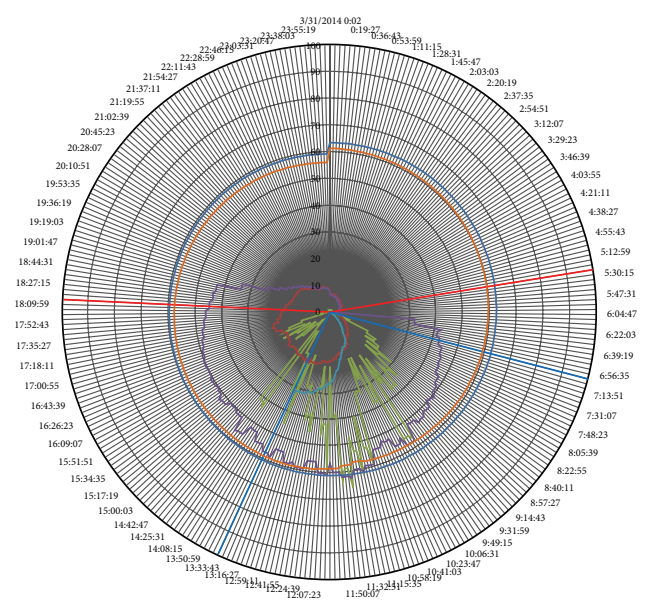

\footnotetext{
- Sunrise and sunset

- Beginning and end of energy production in the system

- Gained energy

- Intensity of solar radiation

- Outdoor temperature

- Temperature in the output of the collectors

— Temperature inside storage tank I

— Temperature inside storage tank II
}

Figure 17: Continued. 


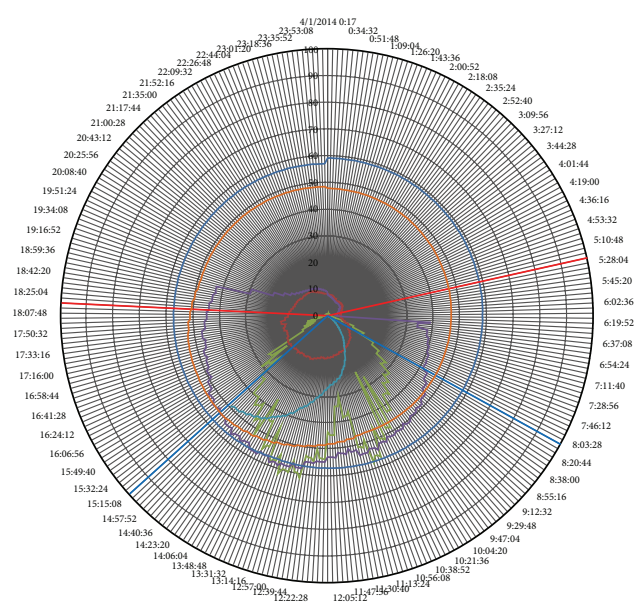

(g)

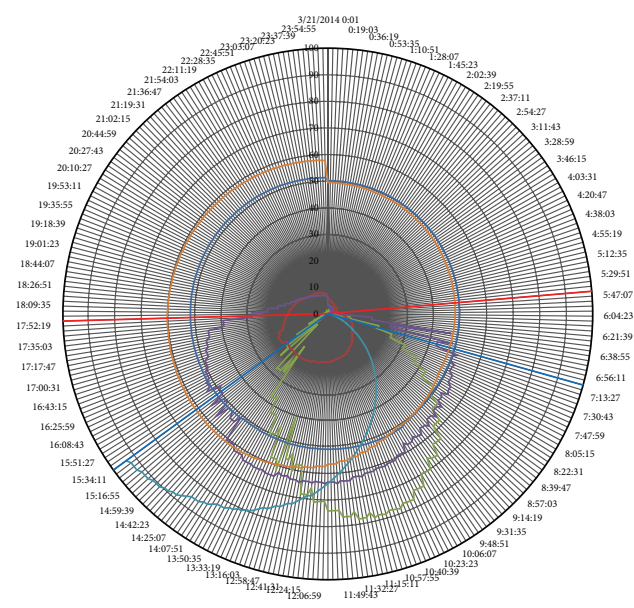

(i)

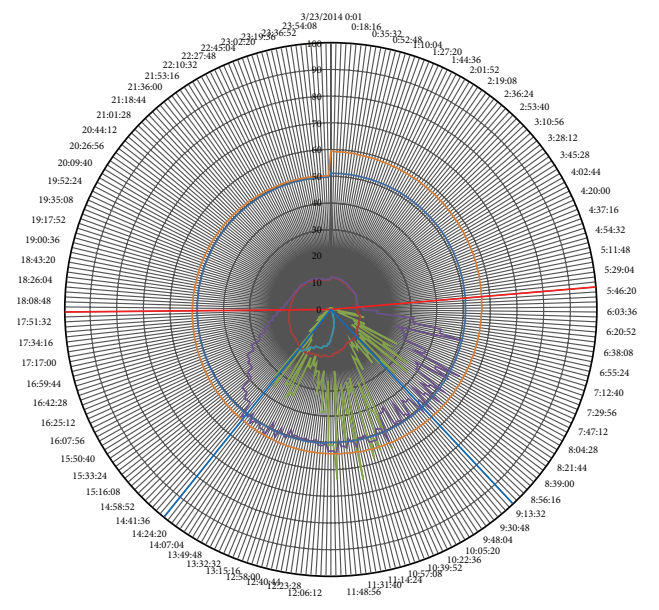

- Sunrise and sunset

_ Beginning and end of energy production in the system

- Gained energy

_ Intensity of solar radiation

- Outdoor temperature

- Temperature in the output of the collectors

_ Temperature inside storage tank I

_ Temperature inside storage tank II

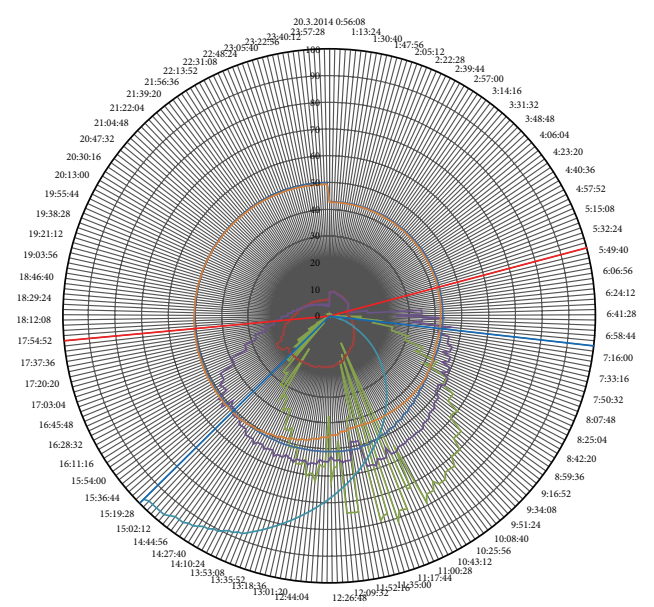

(h)

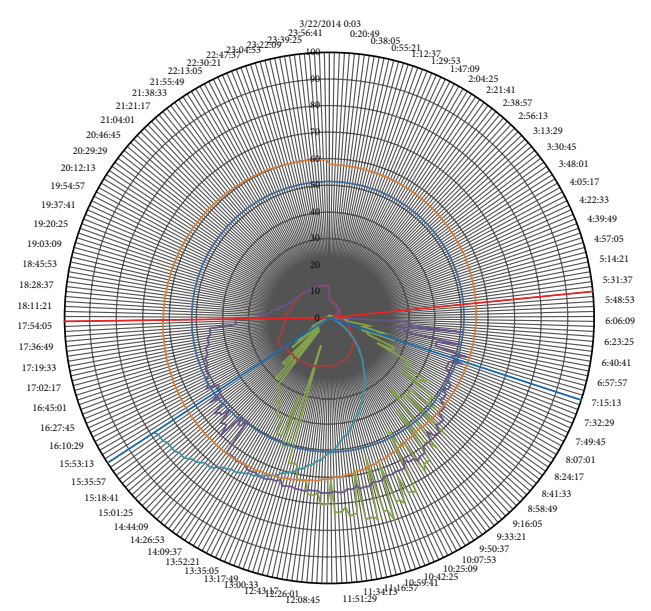

(j)

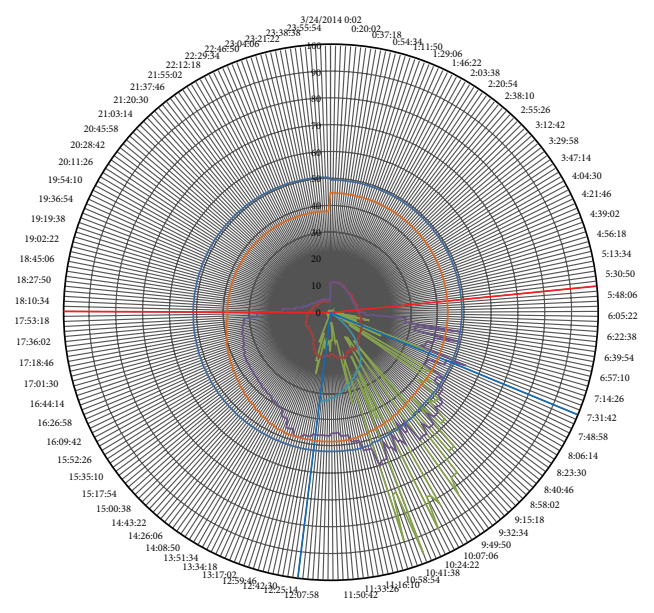

_ Sunrise and sunset

_ Beginning and end of energy production in the system

- Gained energy

_ Intensity of solar radiation

— Outdoor temperature

— Temperature in the output of the collectors

- Temperature inside storage tank I

_ Temperature inside storage tank II

(k)

FIgURE 17: Continued. 

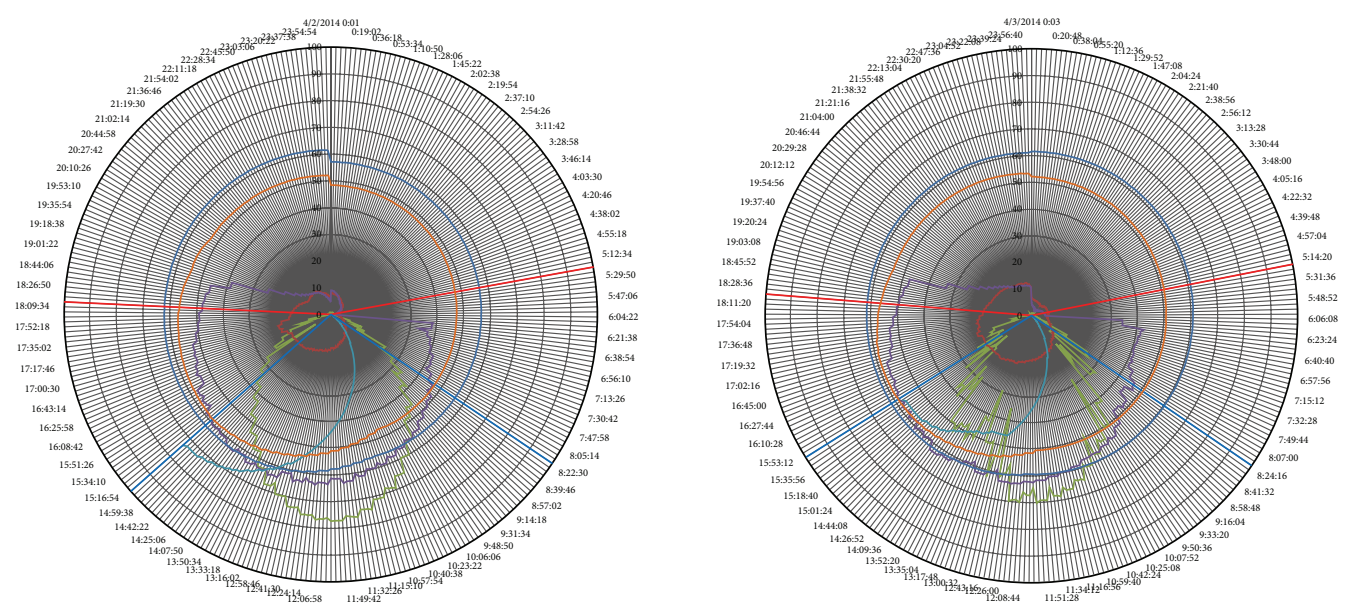

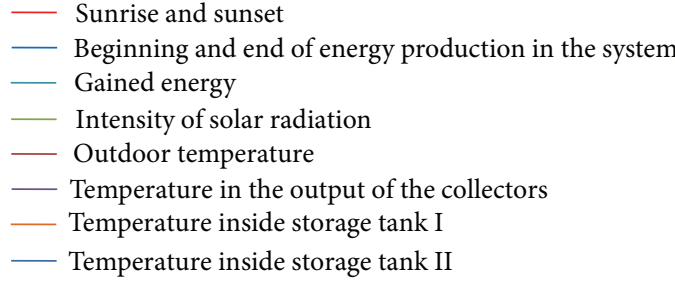

(m)

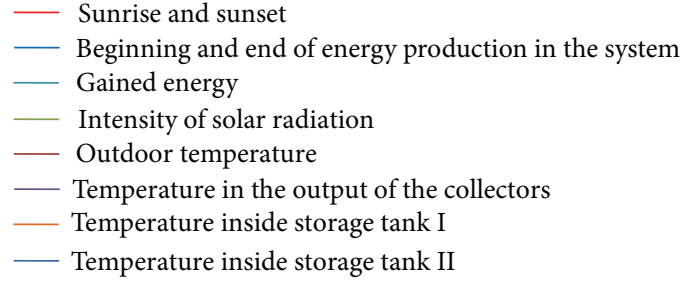

(n)

FIGURE 17: Graphs showing the courses of the monitored values of both the static system $((\mathrm{a})-(\mathrm{g}))$ and the system with rotation $((\mathrm{h})-(\mathrm{n}))$.

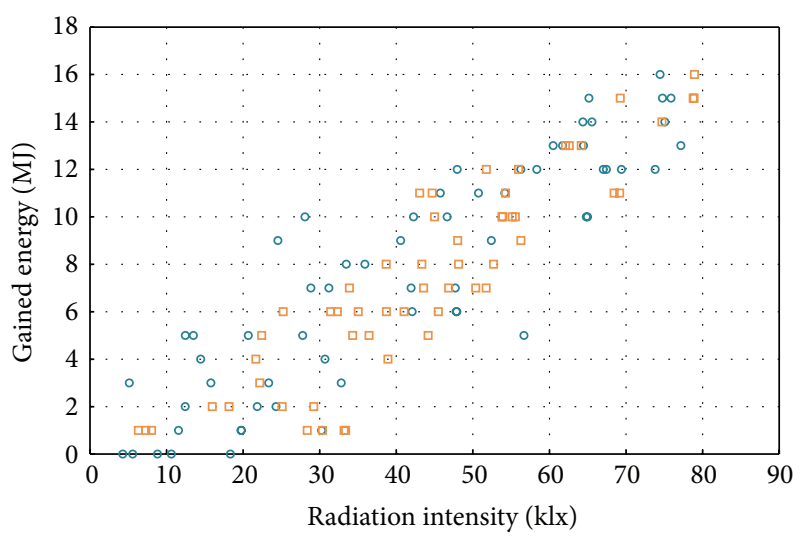

FIGURE 18: The dependence of the produced energy in relation to the radiation intensity.

of the exposure time has a significant impact on the amount of the energy gained. The results are detailed in Figure 19.

The graph of Figure 18 shows the interdependence of the amount of the gained energy by a thermal system in relation to the values of the solar radiation intensity. From the above it follows that it is possible to mutually evaluate the amount of the gained energy, temperature, and the radiation intensity.

Table 2 shows the measured values of the solar radiation intensity and the values of the gained energy for the intervals of 1 hour.

The results of the carried out measurements showed an increase in the amount of the produced energy with the use

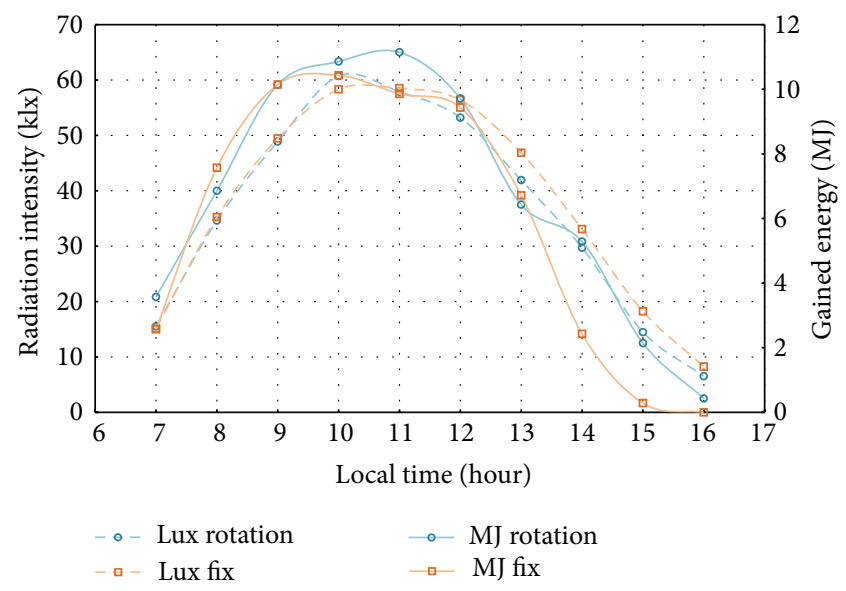

FIGURE 19: The hourly average values for the static system and for the system with rotation.

of a rotary system compared to a static system. During the implementation of the experiment with the rotary system, the total amount of the gained energy was $466 \mathrm{MJ}$. With a static system, this value was $416 \mathrm{MJ}$, which was $89.2 \%$ compared to the system with rotation (Table 2).

Considering the different courses of the radiation intensity during each day of the measurements, see Figures 17(a)17(n), the data were evaluated as average values of the individual sections of the gained energy during the day. The graph in Figure 19 shows the hourly average values for 
TABLE 2: The measured values of the solar radiation intensity and the amount of the gained energy.

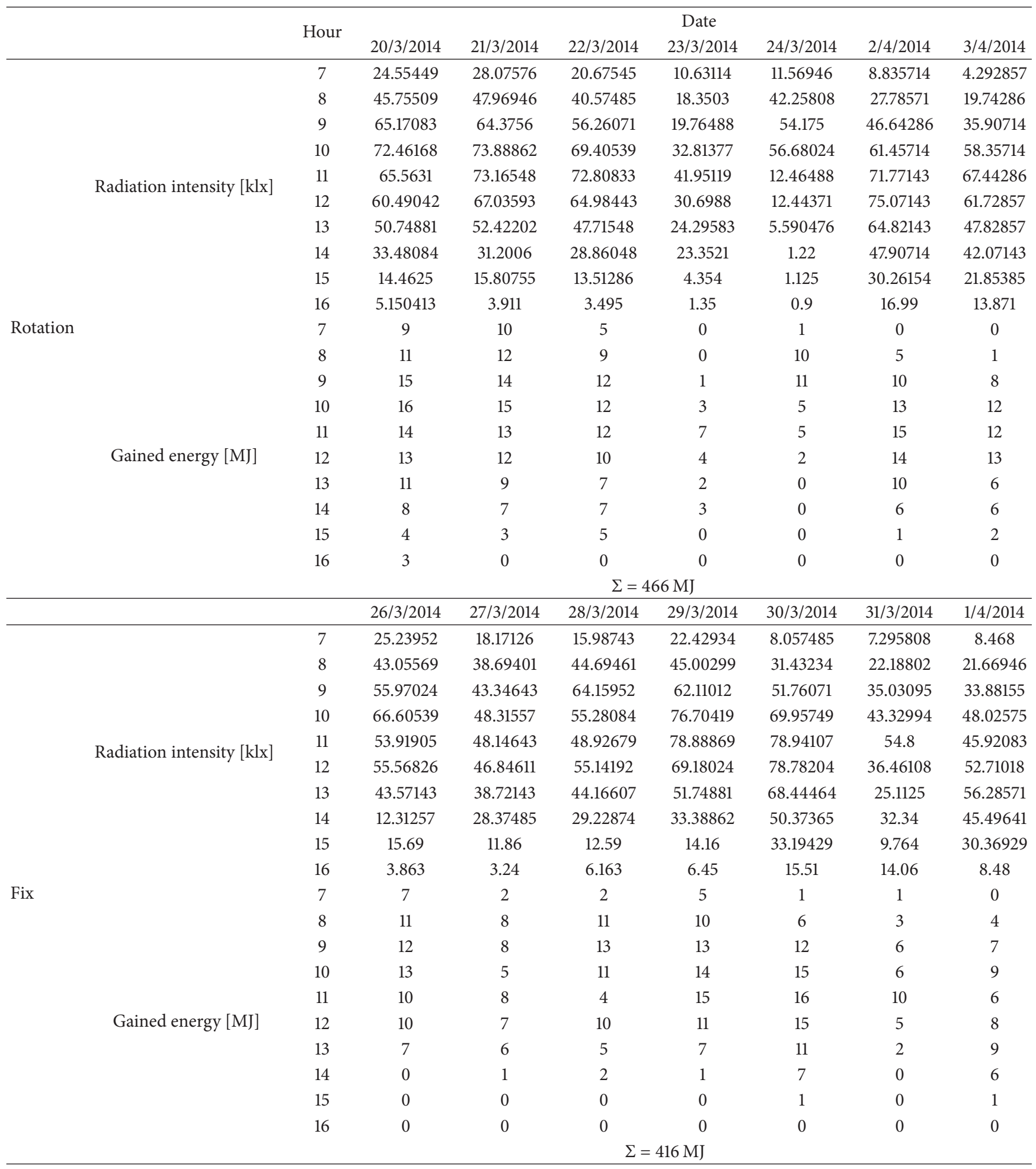

the static system and those for the system with rotation. They also show the courses of the average values of the solar radiation intensity. The graph evidently shows a rise in the amount of the gained energy with the use of a rotary system compared to the static system. In terms of the analysis of a radiation intensity behaviour, in the time interval
7:00-9:30 a.m. it is almost identical with both systems. The amount of energy gained during that time is also about the same. A slight difference in the energy gain at about 8:00 a.m. is caused by a partial overshadowing of the collector caused by the surroundings. The overshadowing is gradually eliminated as the daily height of the Sun above the horizontal 


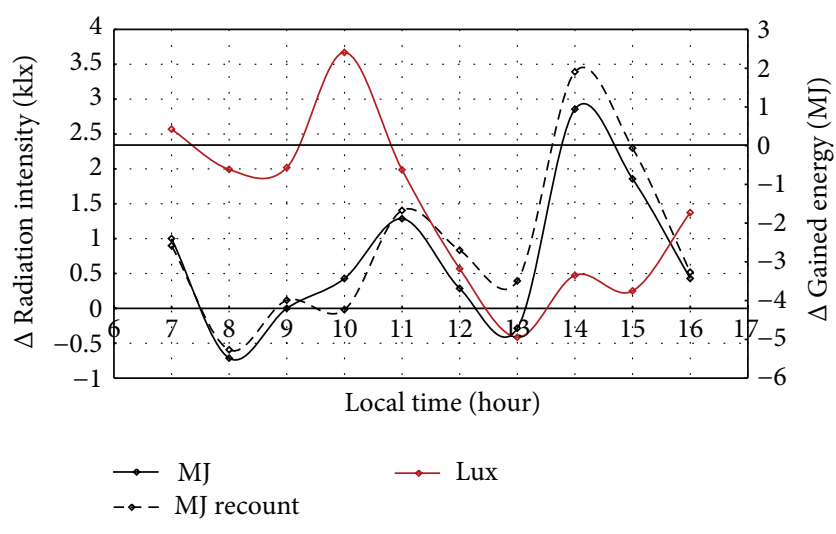

FIgURE 20: The courses of the values differences of the solar radiation intensity and the amount of the gained energy by the rotary system in relation to the fixed system (MJ is the left axis and the intensity is the right axis).

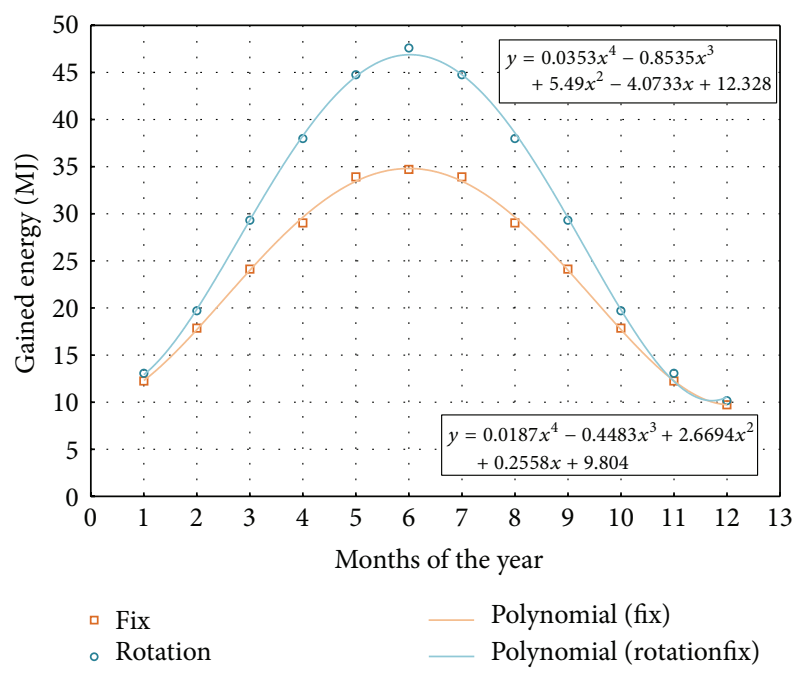

FIGURE 21: Theoretically determined average monthly values of the gained energy for each month throughout the year for both the rotary system and the static system.

plane increases. It means that even if the system is rotating towards the Sun, a part of the collector was overshadowed. The effect of the overshadowing was partially eliminated as the measuring was divided into two stages staring from 03/20/2014 to 24/03/2014 and subsequently from 02/04/2014 to 03/04/2014. Between 9:30 a.m.-11:00 a.m., the importance of a collector rotation is significantly manifested. Between 11:00 a.m. and 1:00 p.m., the position of the collector in relation to the Sun is almost identical with both the fixed system and the rotary system. Therefore, it can be stated that during the abovementioned time the rotation effect is minimum. A significant increase in energy gain is apparent between 1:00 p.m. and 4:00 p.m., when the angle of the incident sunlight upon a fixed collector is unsatisfactory. This fact is greatly compensated by a collector rotation that even at lower values of the radiation intensity allows higher energy gains. In absolute terms, the difference of the gain is 6.7 MJ.

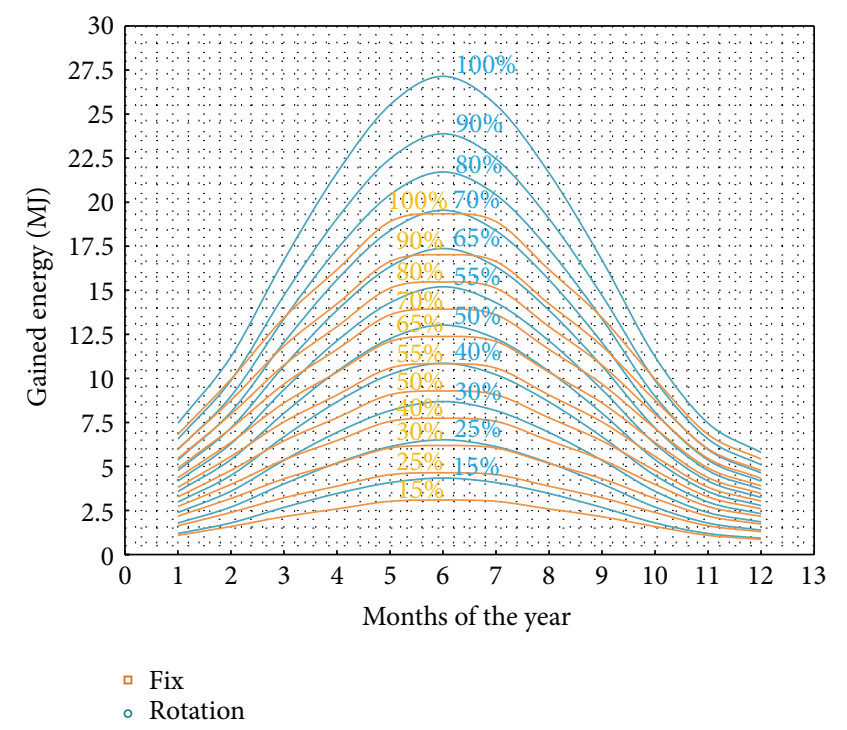

FIGURE 22: Theoretically determined average monthly values of the gained energy for each month throughout the year for the rotary system and the static system based on the change of a global daily light intensity (15\%-100\%).

The course of the values differences of the solar radiation intensity and the amount of the gained energy of the system with rotation in relation to a fixed system are shown in Figure 20. At the same time, the differential courses are determined for the calculated values of the gained energy by the rotary system in relation to the fixed system for the constant values of the radiation intensity during the day.

Based on the measurements, the graphs characterizing the energy gain of the static solar system as well as that of the system with rotary panels (Figures 21 and 22) were constructed for each month of the year. It can be stated that during the equinox, the system with rotation will enable obtaining energy with the same value of the light intensity more efficiently. This represents an increase of the energy absorbed by $23.72 \%$ compared to the amount of energy obtained with the system with a fixed placement of panels.

The individual curves indicate the course of dependence of the potential amount of the produced energy on a calculated global value of a light intensity. The progress of the light intensity is directly related to the cloudiness. Via measurements, the average value of light on a clear day to the value of $80-100 \mathrm{klx}$ was determined. In mild cloudiness, this value represents $60-80 \mathrm{klx}$ and with the cloudiness it is 20-30 klx. When converting to the value of a global daily light intensity, on the average clear day the value is about $2500 \mathrm{klx} /$ day. Based on the course of the graph curves in Figure 22, under the ideal condition (absolutely clear days), with the rotary system when compared to a static system, it is possible to gain up to $40 \%$ extra energy during the summer period.

Taking into account the average annual cloudiness in the given area, which is the interval between $40 \%$ and $50 \%$ per a possible yearly sunshine for the given area, it can be stated that the amount of energy produced by the system with 


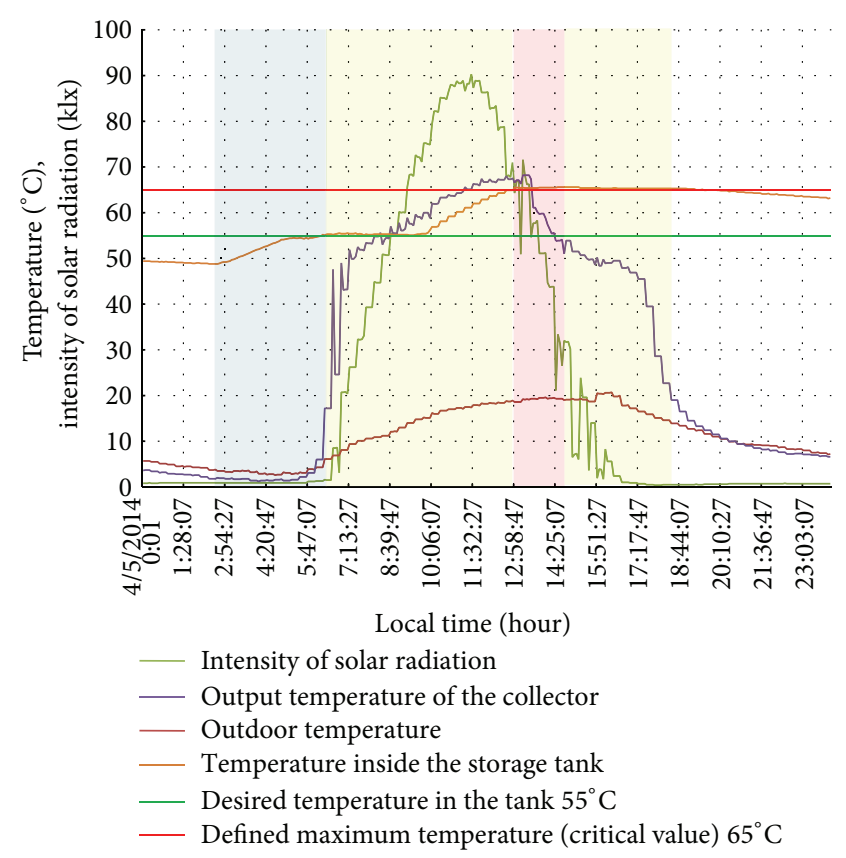

Figure 23: The courses of the monitored values in the experiment on the stagnation correction.

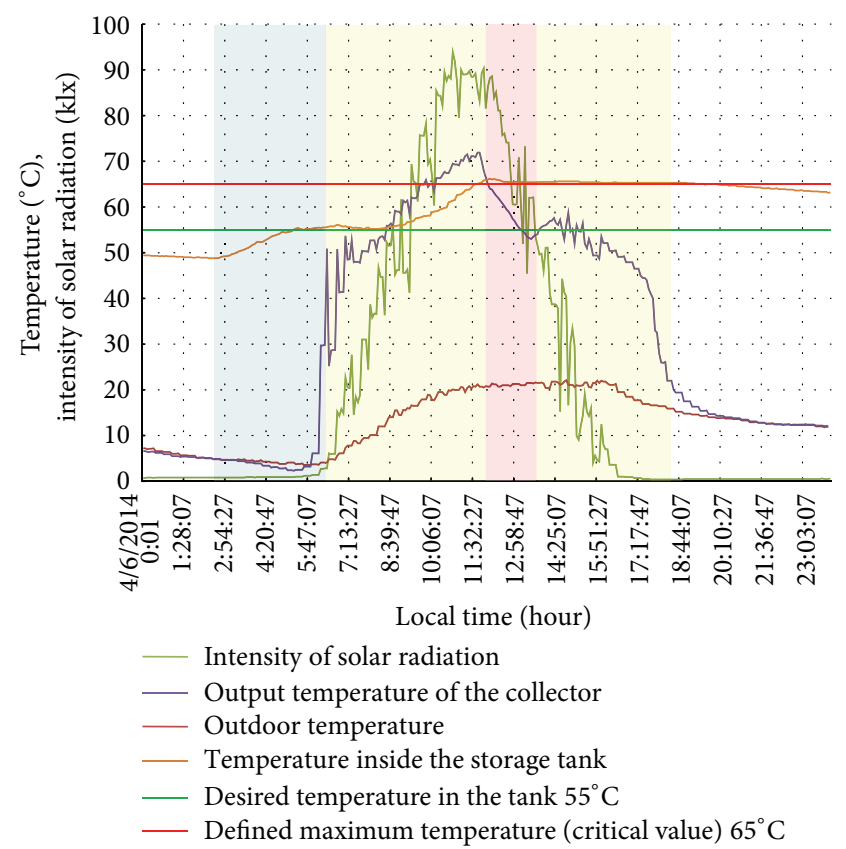

FIGURE 24: The courses of the monitored values in the experiment on the stagnation correction.

rotation in the summer increased by about $25 \%$ compared to the static system. With the decline of sunlight during the day, the efficiency of the rotary system decreases. In the winter months, an increase of profit from the rotary system is $5-10 \%$.

\subsection{Experimental Verification of the Rotary System Operation} with the Elimination of the System Thermal Stagnation. In the case of a rotary system, the temperature of the values achieved in different parts of the solar system can be monitored

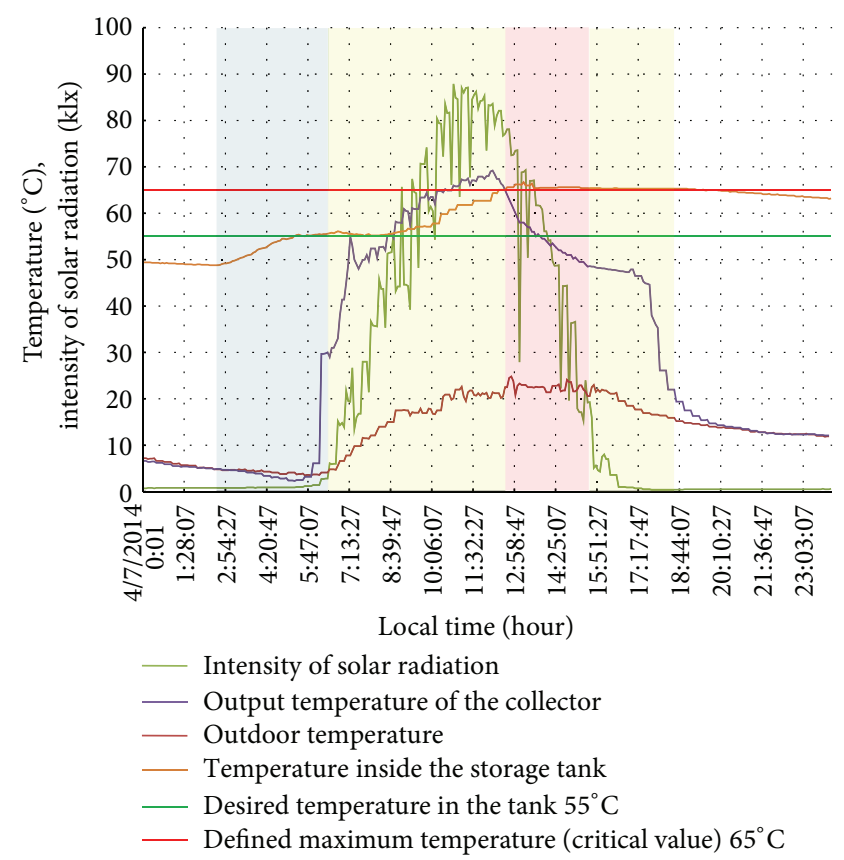

FIGURE 25: The courses of the monitored values in the experiment on the stagnation correction.

by a control algorithm, and in the case of the stagnation condition identification, the correction of the position is provided. In such a case, the collectors are diverted from the incident radiation thus reducing the irradiated area to the value at which the gain will only ensure the compensation of the system energy losses. At lower temperatures in tanks, a recorrection of the system position occurs in order to maximize the possible thermal gain.

The stagnation condition was ensured by the creation of a new structure of the system via the secondary tank disconnection. The primary tank was charged by the external source (a gas boiler) so that the temperature in the tank was about $55^{\circ} \mathrm{C}$. Thus prepared system was activated at sunrise. As it can be seen in the graph, the pump was switched on when the required output temperature of the collector was reached as described in the previous experiment. Consequently, the system was charged to achieve the defined maximum temperature. For the experimental verification, the maximum temperature was adjusted to the value of $65^{\circ} \mathrm{C}$. Beyond the defined maximum temperature, on the basis of the modified algorithm, the system turned the panels into the position relative to the sun so that the proportion of the irradiated surface corresponded to the desired heat gain. In the iterations proportional to a time constant, the temperature of the medium in the tank as well as that in the output and input to the system is evaluated. If the temperature falls, the system corrects the panels position in relation to the current ecliptic so as to increase the size of the irradiated surface. The graphs in Figures 23-25 show the course of the observed values in the carried out experiment.

The graphs in Figures 23-25 show the repeated experiments on the operation verification of the system of thermal collectors rotation with the elimination of the system thermal 
stagnation. The information contained in the graphs provides a picture of the behaviour of the observed variables. It is necessary to form an overall picture owing to the fact that the experiment was carried out during the period of a changeable weather. The individual values behaviours complement each other in interpretations. If the individual changes were not sufficiently documented, it would not be possible to interpret the obtained results sufficiently precisely. After reaching the critical value $\left(65^{\circ} \mathrm{C}\right)$, the control system turned the panels to the end position. This resulted in a decrease in the irradiated area as well as a significant increase in the angle from the incident sunbeams. A significant decline in the efficiency of solar panels occurred. Subsequently, the temperature in the output of the collectors dropped with respect to the natural balancing of energy benefit of ambient environment and panels (gradual cooling of panels).

\section{Conclusion}

Based on the carried out experiments, several important findings can be highlighted. The rotary system of the thermal panels plays an important role not only in increasing efficiency but also in the elimination of thermal stagnation. The results show a significant increase in thermal energy gain by about $23 \%$ in the period of the year with a relatively low number of hours of sunshine when compared to the summer maxima. Based on the evaluation, along with the increasing duration of a daily sunshine, there was the increase in the rotary system efficiency (Figure 22). Theoretically, in the summer time, there is an energy gain up to $40 \%$ compared to the static system without rotation. In winter, the gain is lower and varies in the interval between $5 \%$ and $10 \%$.

In repeated experiments, the efficiency of rotation was demonstrated as an important and technically feasible method of the system overheating elimination. Based on the described results it also follows that the system is effective enough to ensure a safe autonomous functioning.

The results of the experimental measurements have demonstrated the ability of the system to avoid the undesired temperature rise in the system. While experimenting, the critical value of temperature was determined to $65^{\circ} \mathrm{C}$. After reaching the critical temperature, the control system turned the construction to the end position which led to a significant change of the angle of incidence. Owing to a decrease in energy striking the collector, the temperature rise was reduced, which after the procedure starting increased in the collectors by about $10 \%$ above the critical temperature, subsequently it gradually began to decline. The temperature rise is within the safe interval, which does not constitute a risk when achieving the system stagnation.

\section{Nomenclature}

$\delta: \quad$ The solar declination

$n$ : The day of the year

$\mathrm{S}, \mathrm{N}$ : Cardinal points

$h_{0}$ : Height of the Sun

$\theta$ : The angle between a surface normal and sunbeams $\beta$ : $\quad$ A tilt angle of collectors area from a horizontal plane

$a_{n}^{S}: \quad$ Azimuth of the normal from the south

$a_{s}^{S}$ : The azimuth of the Sun from the south

$G$ : $\quad$ Global irradiance

$G_{t}$ : Total solar irradiance

$G_{b}$ : Direct horizontal irradiance

$G_{d}: \quad$ Diffuse irradiance

$G_{r}: \quad$ Reflected irradiance

$I_{0}$ : Solar constant

$I_{b n}$ : Intensity of solar energy incident on the Earth's

$T_{L}$ : The coefficient of atmospheric pollution

A: The coefficient depending on the height of the Sun above the horizon

$\rho: \quad$ A reflectivity

DHW: Domestic hot water.

\section{Conflict of Interests}

The authors declare that there is no conflict of interests regarding the publication of this paper.

\section{References}

[1] E. Nagy, Low Energy and Energetic Passive House, Jaga Group, Bratislava, Slovakia, 2009.

[2] J. S. Bojanowski, A. Vrieling, and A. K. Skidmore, "A comparison of data sources for creating a long-term time series of daily gridded solar radiation for Europe," Solar Energy, vol. 99, pp. 152-171, 2014.

[3] M. Halahyja and J. Valášek, Solar Energy and Its Utilization, Alfa, Bratislava, Slovakia, 1985.

[4] J. Cihelka, Solar Heating Systems, SNTL, Praha, Slovakia, 1984.

[5] J. Trnavský and K. Duríková, "Energy from nature," in Everything about the Construction of Energy-Efficient House, vol. 5, pp. 74-78, 2010.

[6] Y. Tian and C. Y. Zhao, "A review of solar collectors and thermal energy storage in solar thermal applications," Applied Energy, vol. 104, pp. 538-553, 2013.

[7] H. Moghadam, F. F. Tabrizi, and A. Z. Sharak, "Optimization of solar flat collector inclination," Desalination, vol. 265, no. 1-3, pp. 107-111, 2011.

[8] M. Rimár, I. Corny, M. Fedak, and S. Kuna, "Experimental study on energy gain of the solar collector with automatic inclining system in conditions of central europe during low solar potential periods," Applied Mechanics and Materials, vol. 415, pp. 26-29, 2013.

[9] C. Stanciu and D. Stanciu, "Optimum tilt angle for flat plate collectors all over the World-a declination dependence formula and comparisons of three solar radiation models," Energy Conversion and Management, vol. 81, pp. 133-143, 2014.

[10] M. Benghanem, "Optimization of tilt angle for solar panel: case study for Madinah, Saudi Arabia," Applied Energy, vol. 88, no. 4, pp. 1427-1433, 2011.

[11] C. P. Jacovides, F. S. Tymvios, V. D. Assimakopoulos, and N. A. Kaltsounides, "Comparative study of various correlations in estimating hourly diffuse fraction of global solar radiation," Renewable Energy, vol. 31, no. 15, pp. 2492-2504, 2006. 
[12] K. H. Remmers, Large Solar Installations, ERA, Brno, Czech Republic, 2007.

[13] I. Corny and M. Fedak, "Technical parameters of solar thermal collectors and their measurement," in Proceedings of the Technology Systems Operation Conference (TSO '07), pp. 2-3, FVT TU, Presov, Slovakia, 2007.

[14] O. Lulkovicová and J. Takács, Untraditional Energy Sources, STU-SF, Bratislava, Slovakia, 2003.

[15] I. Čorný, "Behaviour of thermal solar systems at stagnation," Manufacturing Engineering, vol. 6, no. 3, pp. 79-80, 2007.

[16] S. Harrisona and C. A. Cruickshank, "A review of strategies for the control of high temperature stagnation in solar collectors and systems," Energy Procedia, vol. 30, pp. 793-804, 2012.

[17] Z. Xinyu, Y. Shijun, X. Wei et al., "Test result analysis of the stagnation effect on the thermal performance of solar collector," Energy Procedia, vol. 30, pp. 824-828, 2012.

[18] H. P. Garg and G. Datta, "Fundamentals and characteristics of solar radiation," Renewable Energy, vol. 3, no. 4-5, pp. 305-319, 1993.

[19] K. K. Gopinathan and A. Soler, "Effect of sunshine and solar declination on the computation of monthly mean daily diffuse solar radiation," Renewable Energy, vol. 7, no. 1, pp. 89-93, 1996.

[20] K. Mohammadi, S. Shamshirband, M. H. Anisi, K. A. Alam, and D. Petković, "Support vector regression based prediction of global solar radiation on a horizontal surface," Energy Conversion and Management, vol. 91, pp. 433-441, 2015.

[21] H. K. Seidlitz, S. Thiel, A. Krins, and H. Mayer, "Solar radiation at the Earth's surface," in Sun Protection in Man, chapter 36, Elsevier, 2001.

[22] J. F. Lee, N. A. Rahim, and Y. A. Al-Turki, "Performance of dualaxis solar tracker versus static solar system by segmented clearness index in Malaysia," International Journal of Photoenergy, vol. 2013, Article ID 820714, 13 pages, 2013.

[23] H. Li, W. Ma, X. Wang, and Y. Lian, "Estimating monthly average daily diffuse solar radiation with multiple predictors: a case study," Renewable Energy, vol. 36, no. 7, pp. 1944-1948, 2011.

[24] T. Muneer, S. Younes, and S. Munawwar, "Discourses on solar radiation modeling," Renewable and Sustainable Energy Reviews, vol. 11, no. 4, pp. 551-602, 2007.

[25] T. Matuška, Solar Installations in Examples, Grada Publishing, Prague, Czech Republic, 2013.

[26] G. N. Tiwari, Solar Energy Technology Advances, Nova Science Publishers, New York, NY, USA, 2006.

[27] M. Paulescu, E. Paulescu, P. Gravila, and V. Badescu, "Solar radiation measurements green energy and technology," in Weather Modeling and Forecasting of PV Systems Operation, chapter 2, Springer, London, UK, 2013.

[28] W. Yao, Z. Li, Y. Wang, F. Jiang, and L. Hu, "Evaluation of global solar radiation models for Shanghai, China," Energy Conversion and Management, vol. 84, pp. 597-612, 2014.

[29] M. Rimár and Š. Kuna, "Loops control structure and solar system control of a multivalent laboratory under real-time mode," Applied Mechanics and Materials, vol. 616, pp. 135-142, 2014.

[30] M. Rimár, Monitoring Systems, FVT TU, Prešov, Slovakia, 2013.

[31] A. Panda, Monitorovanie a Hodnotenie Procesov, FVT TU, Prešov, Slovakia, 2014.

[32] J. Pitel', Unconventional Drives for Manipulation Devices, SEKEL, VUT, Brno, Czech Republic, 2009.

[33] T. Zaborowski, J. Jurko, and A. Panda, Assembly ProcessesTheory and Technology, IBEN, Gorzów, Poland, 2014.
[34] J. Pitel' and M. Rimár, "Classical and non-conventional drives for automatic manipulation devices," Acta Mechanica Slovaca, vol. 12, no. 1-A/2008, pp. 167-172, 2008.

[35] A. Panda, M. Jančík, and I. Pandová, "Influence of nonlinearity on the safety," Pogranicza Technik, IBEN, Gorzów, Poland, 2013.

[36] J. Zajac and I. Vojtko, "Monitoring systems machinist," in Nové smery vo výrobných technológiách, pp. 594-597, Technical University of Košice, Košice, Slovakia, 2004.

[37] M. Rimár and P. Jacko, "Riadenie elektrohydraulického servopohonu s dynamickým zat'ažením," in Automatizácia a riadenie $v$ teórii a praxi ARTEP, pp. 54/1-54/8, Technical University of Košice, Košice, Slovakia, 2009.

[38] I. Čorný, L'. Straka, and J. Mihalčová, “Konvekčné modely a ich aplikácia v simulačných programoch v technike prostredia," Strojárstvo Extra, no. 5, pp. 6/1-6/4, 2009.

[39] J. Pitel', Measurement and Diagnostics, FVT TU, Prešov, Slovakia, 2008.

[40] T. Krenický, "Flexible approach to monitoring of mechatronic systems," Strojárstvo, vol. 17, no. 9, pp. 104-105, 2013.

[41] T. Krenický and P. Jacko, "Real-time monitoring of the technical systems operation," Strojárstvo Extra, no. 5, pp. 32/1-32/2, 2011.

[42] Slovak Hydrometeorological Institute, http://www.shmu.sk/en/ ?page $=1064$. 

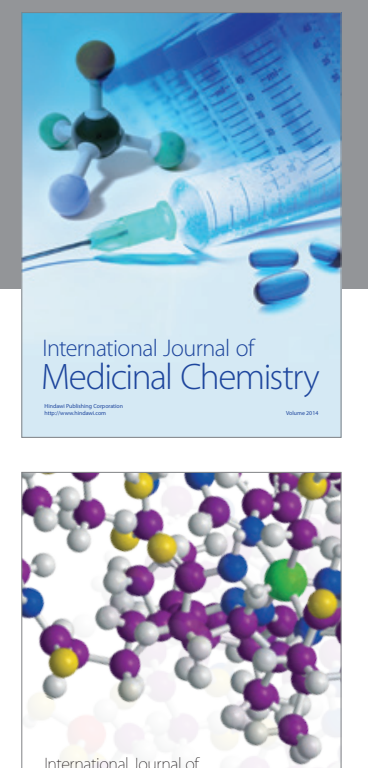

\section{Carbohydrate} Chemistry

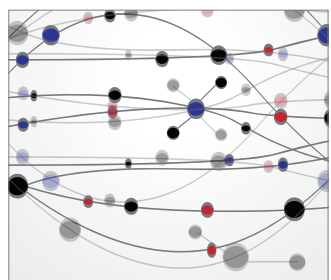

The Scientific World Journal
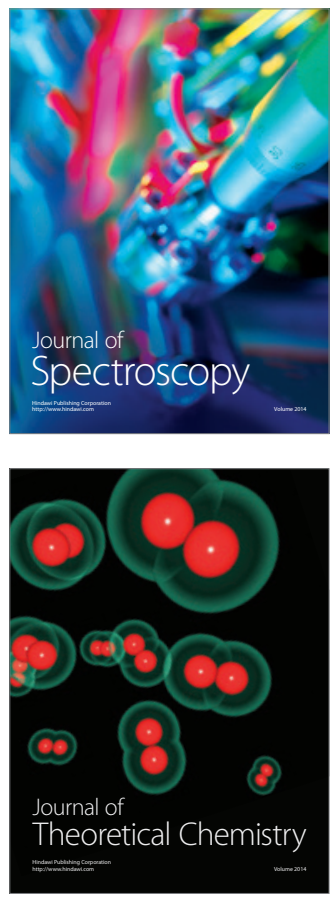
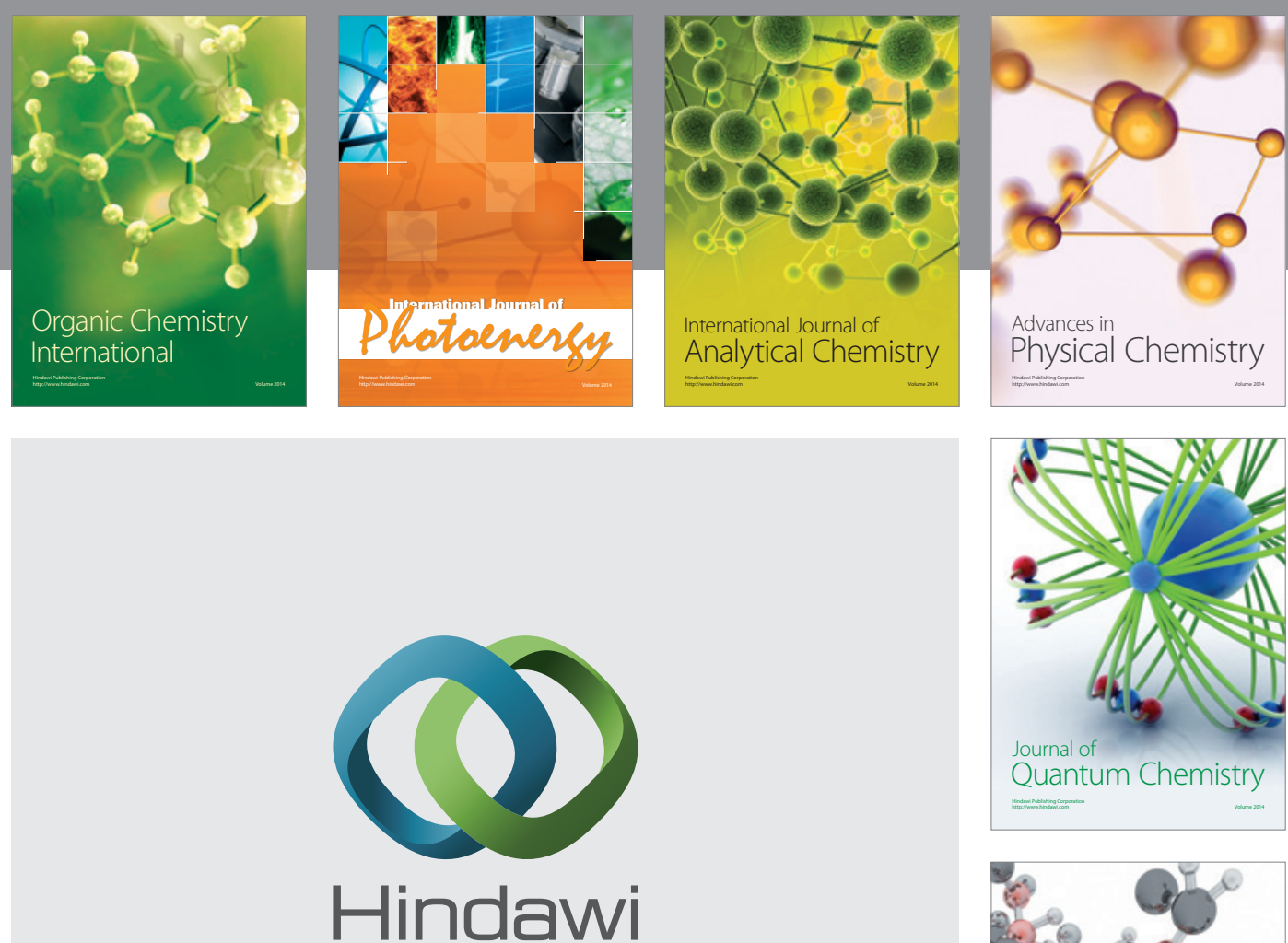

Submit your manuscripts at

http://www.hindawi.com

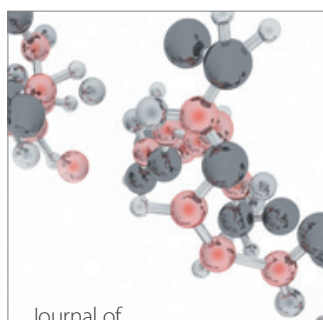

Analytical Methods

in Chemistry

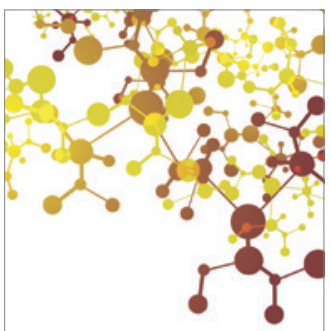

Journal of

Applied Chemistry

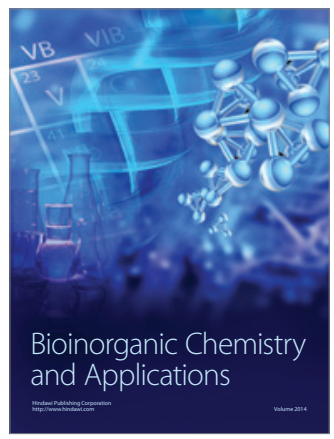

Inorganic Chemistry
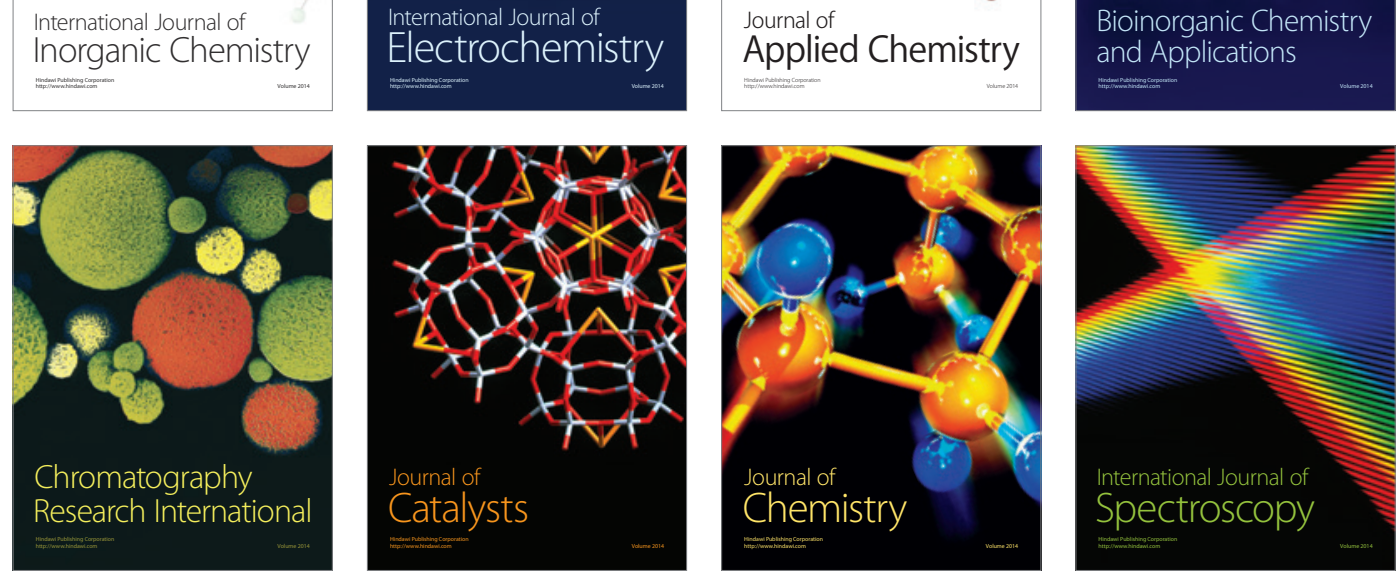